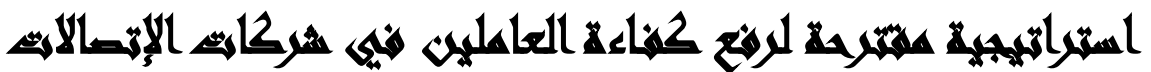

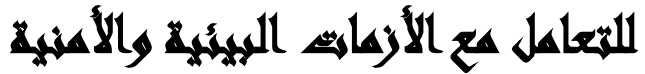

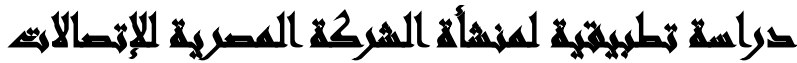

$[1 \wedge]$

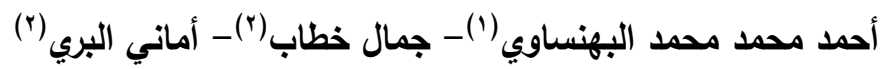

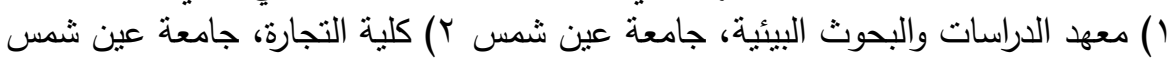

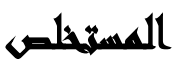

يعتبر دور شركات الإتصالات من الأدوار الهامة فى حباتتا اليومية المعاصرة مما ينبغى دراتي

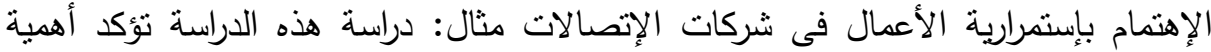

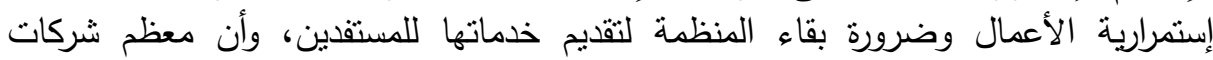

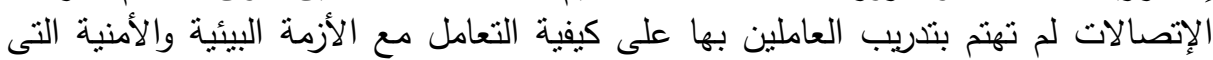

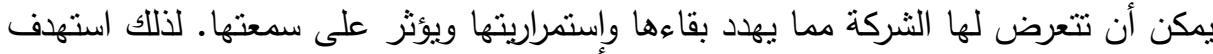

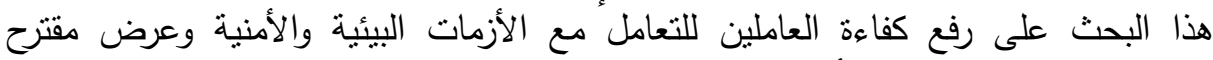

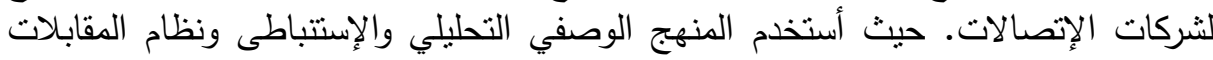

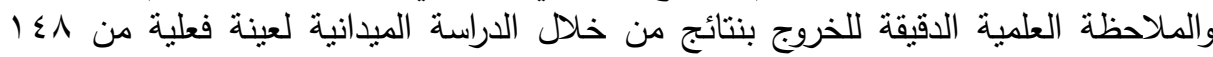

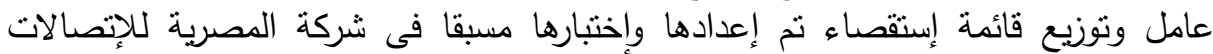
بالقرية الذكية للتوصل إلى مدى مستوى تدريب وكفاءة العاملين للتعامل مع الأزمات التهات

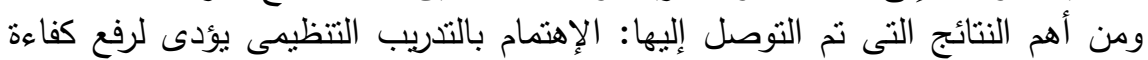

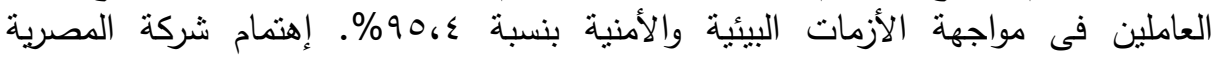

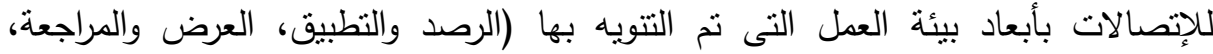

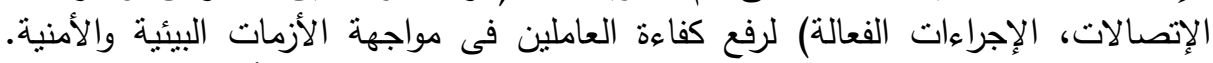

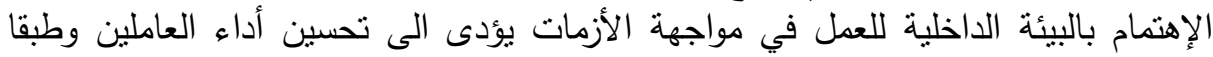

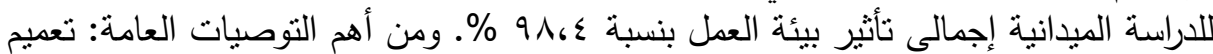

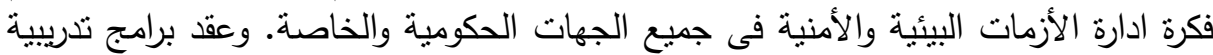

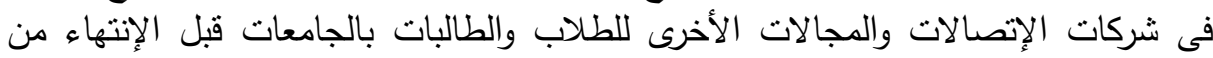

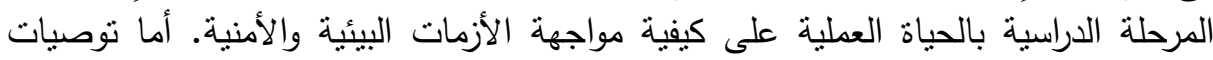

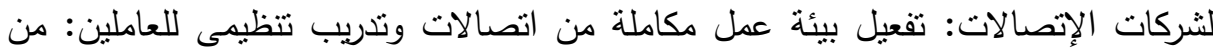

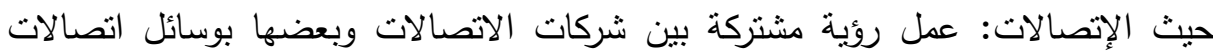

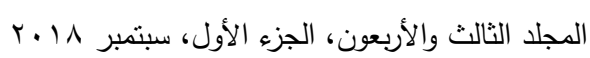


حديثة منل فيديوكونفرنس، أما من حيث التدريب التتظيمى: تحديد ميزانية مالية لعمل بيئة

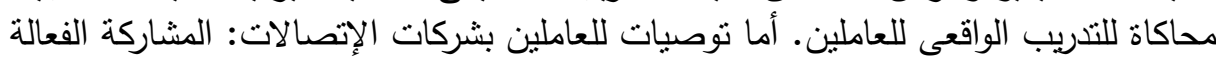

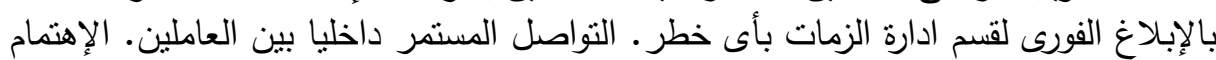
بالتدريب المستمر والتطوير وقراءة النشرات وحضور الندوات الندات الخاصة بطرق مواجهة الأزمات.

\section{المهنبمة}

يصبح العالم حولنا شاهدا على التطور التكنولوجى المتلاحق في وسائل الإتصال وأهميتها للأفراد والمنظمات والعلاقات الدولية في الوقت الحديث، حيث يعد نظام الاتصالات هوالثريان الرئيسي الذي يغذي المنظمة داخليا وخارجيا، ويتم من خلاله تبادل الآراء، الأفكار ،

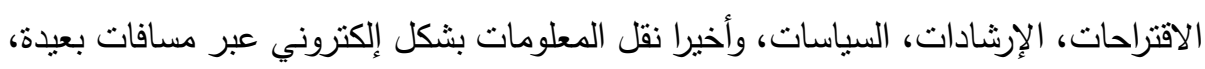
وله أثز كبير وفعال في بناء وتطور المنظمات والثركات. نظرا للتطور التكنولوجى العالمى فقد يحدث أزمات متعددة، فيجب علي ولئ جميع المنظمات

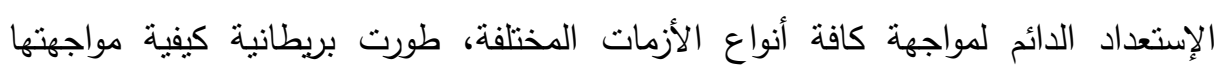

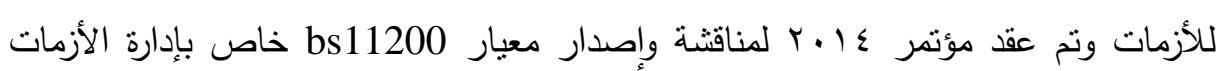

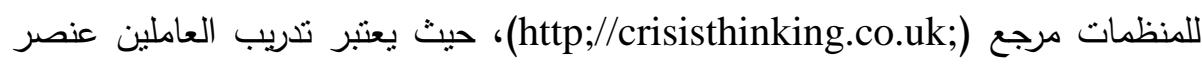

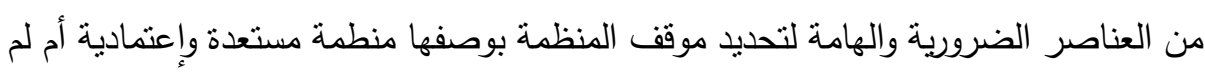
تكن مستعدة لمواجهة الأزمة، يوجد مؤسسة تسمى \& \&

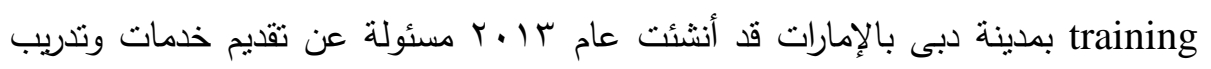

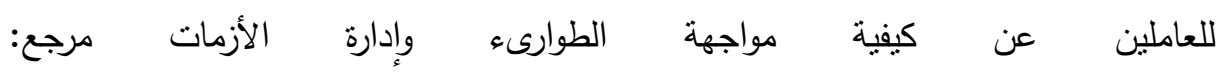
ل) (corina@marajasonconsulting.com)، فلابد من وضع خطط تدربيية منطورة طبقا

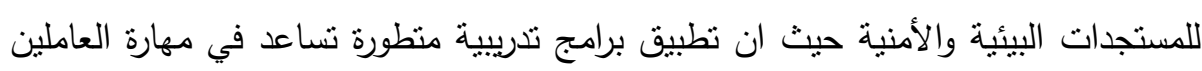

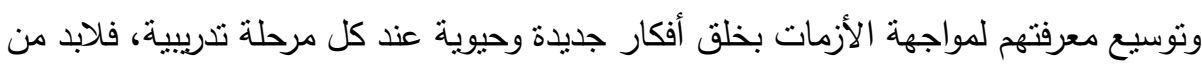

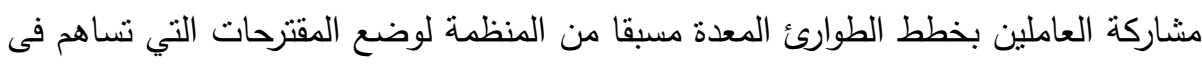

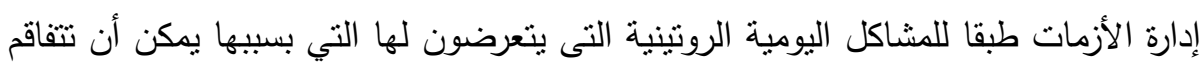
ويحدث أزمة، فهذه الدراسة سوف تحدد صور التدريب المختلفة للعاملين عن طريق فرق العمل بلتئل 
مجلة العلوم البيئية

معهد الدراسات والبحوث البيئية - جامعة عين شمس لئ

المشتركة وتحديد العوامل الرئيسية الهامة لتحقيق مستوى كفاءة جيد للعاملين لمواجهة الأزمات البيئية والأمنية في شركات الإتصالات.

\section{Aand}

يعتبر دور شركات الإتصالات ضرورى لتواصل المواطنين والدول فيما بينهم، لم تهنم بعض شركات الإتصالات بالتدريب العملى الدورى للعاملين على مواجهة الأزمات البيئية

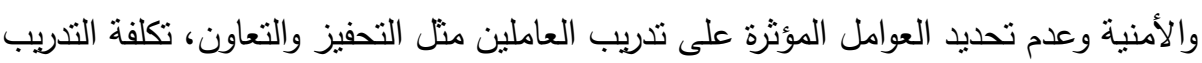

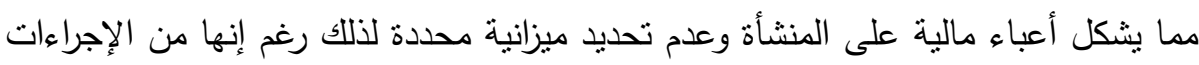

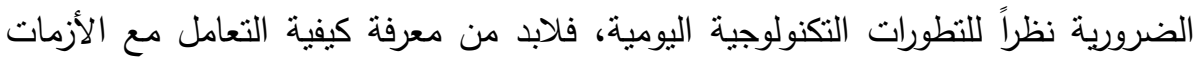
وتدريب العاملين على ذلك لضمان إستمرارية العمل بها.

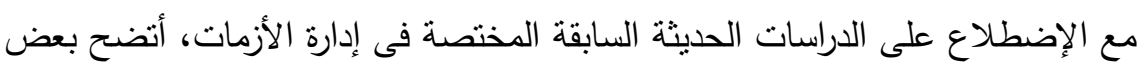
الدراسات تهنم بتوضيح ومحاولة حل تللك المشكلات فى تدريب العاملين على مواجهة الأزمات

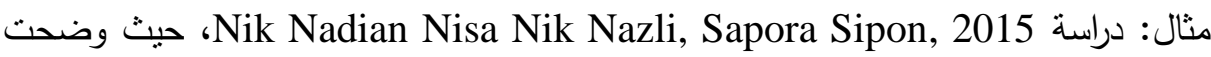
Marie ) تلك الدراسة العوامل المؤثرة على التدريب ولم تهتم بعملية التدريب ذاتها؛ دراسة Andersson 2014 ) ضرورة تدريب الطلاب فى الجامعات على مواجهة الأزمات والطوارىء قبل التخرج من المرحلة الجامعية ولم توضح طرق التدريب؛ دراسة: Katerina) Vichova, Martin Hromada, David Rehak, 2017) لإدارة الأزمات وأيضا لم تهتم بتدريب العاملين، من هذا الإتجاه ظهرت مشكلة البحث حيث لا توجد دراسة سابقة حديثة اتجهت لطرق التدريب للعاملين على مواجهة الأزمات لذلك سيتم

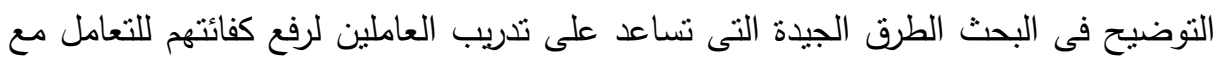
الأزمات البيئية والأمنية فى شركات الإتصالات.

\section{تمساولايت المهمه}

• ما أبعاد بيئة العمل الجيدة للعاملين لرفع مستوى كفائتهم فى مواجهة الأزمات البيئية

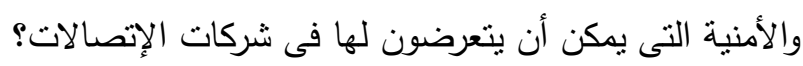

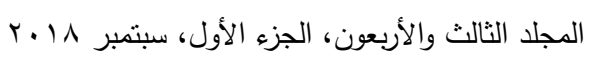


• ما الإجراءات الفعالة التى يجب إتخاذها لرفع مستوى كفاءة العاملين فى مواجهة الأزمات

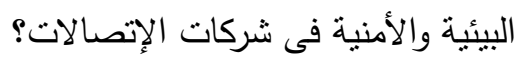

• ما التصور المقترح لرفع كفاءة العاملين للتعامل مع الأزمات البيئية والأمنية فى شركات

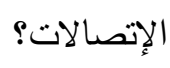

\section{أهسا اهن الهيهـ}

الهدف الرئيسى للبحث هو كيفية رفع مستوى كفاءة العاملين للتعامل مع الأزمات البيئية

$$
\text { والأمنية في شركات الإتصالات. }
$$

$$
\text { ولكى يتحقق الهدف الرئيسى، فلابد من تحقيق أهداف فرعية أخرى: }
$$

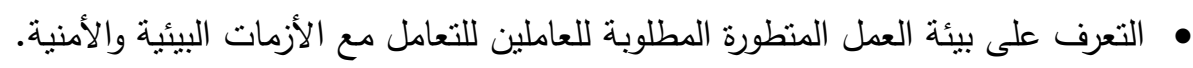

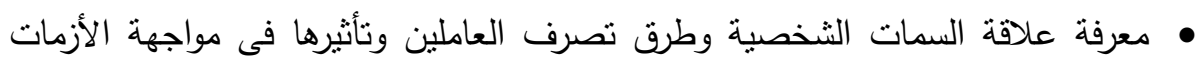

$$
\text { البيئية والأمنية. }
$$

• التعرف على الإجراءات الفعالة المطلوبة التى تناعد العاملين فى تعاملهم مع الأزمات

$$
\text { البيئية والأمنية. }
$$

ومن خلال الأهداف الفرعية الهدف الرئيسى.

يتحقق

\section{هورغ الهيمث}

الفرض الرئيسى الأول: يوجد علاقة ذات دلالة إحصائية لبيئة العمل بأبعدها المختلفة على مستوى كفاءة أداء العاملين للتعامل مع الأزمات البيئية والأمنية. وينبثق منه الفروض الفرعية الآتية:

الفرض الفرعى الأول: يوجد علاقة أثر ذات دلالة إحصائية لبعد الإتصالات على مستوى كفاءة أداء العاملين للتعامل مع الأزمات البيئية والأمنية. الفرض الفرعى الثانى: يوجد علاقة أثز ذات دلالة إحصائية لبعد مبادرة التدريب التتظيمى التهاتي والمكتسب على مستوى كفاءة أداء العاملين للتعامل مع الأزمات البيئية والأمنية. 
الفرض الفرعى الثالث: يوجد علاقة أثز ذات دلالة إحصائية لبعد الإجراءات الفعالة على مستوى كفاءة أداء العاملين للنعامل مع الأزمات البيئية والأمنية. الفرض الفرعى الرابع: يوجد علاقة أثز ذات دلالة إحصائية لبعد الرقابة على مستوى كفاءة التهاءئه أداء العاملين للتعامل مع الأزمات البيئية والأمنية.

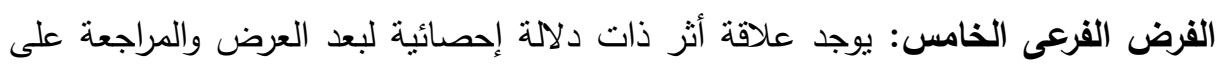
مستوى كفاءة أداء العاملين للتعامل مع الأزمات البيئية والأمنية.

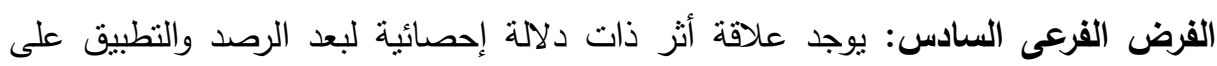
مستوى كفاءة أداء العاملين للتعامل مع الأزمات البيئية والأمنية. الفرض الرئيسى الثانى: يوجد فروق ذات دلالة إحصائية فى إستجابات المستقصى منهم حول أبعاد بيئة العمل تبعا للمتغيرات التالية (النوع، العمر ، المؤهل العلمى). الفرض الرئيسى الثالث: يوجد فروق ذات دلالة إحصائية فى إستجابات المستقصى منهم حول مستوى كفاءة أداء العاملين تبعا للمتغيرات التالية (النوع، العمر ، المؤهل العلمى).

\section{AMوל الهAهA}

حدود مكانية: منشأة المصرية للاتصالات بالقرية الذكية.

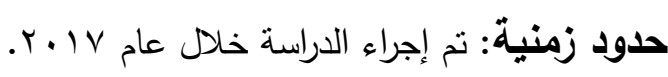

\section{منهمج الدواسمة}

اعتمد الباحث في هذه الدراسة المنهج الوصفي التحليلي وأسلوب الدراسة الميدانية لجمع

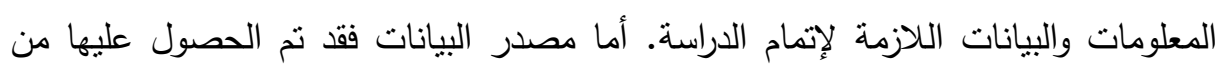
مصدرين هما: • المصادر الثانوية: حيث اتجه الباحث في معالجة الإطار النظري للاراسة إلى مصادر

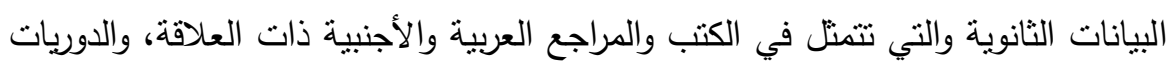

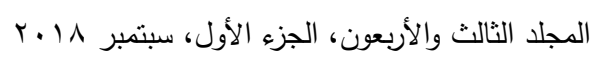


والمقالات والتقارير، والأبحاث والدراسات السابقة الني تتاولت موضوع الدارسة، والبحث والمطالعة في مواقع الإنترنت المختلفة. • المصادر الأولية: وتتمثل في جمع البيانات الأولية ميدانياً.

\section{أهمية المبحث}

إن هذه الدراسة تسهم فى تسليط الضوء على ضرورة رفع مهارة العاملين لمواجهة الأزمة

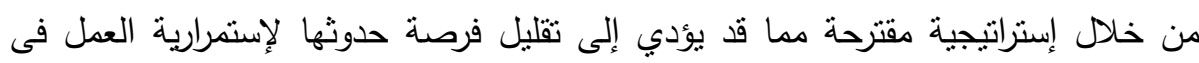
شركات الإتصالات حيث أصبح دور تكنولوجيا الإتصالات في حياتتا هام جداً وتحقيق المزيد

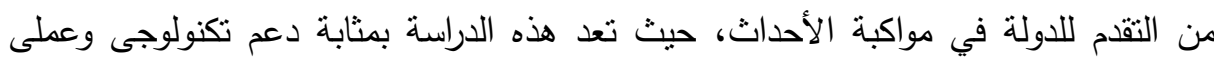

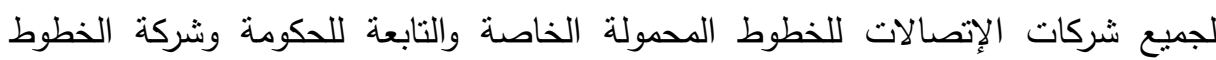
الأرضية الحكومية والعاملين بتلك الثركات.

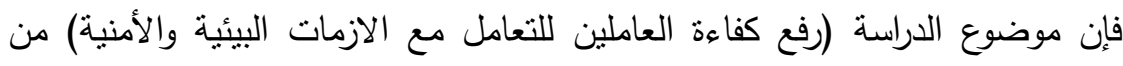

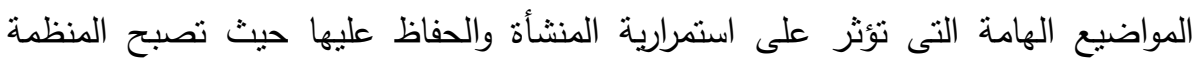
مستعدة للأزمات، غير مستهدفة وضمان إستمرار خدمة الإتصالات لجميع العملاء.

\section{التراسايت الهابرية}

دراسة Adelaida Fanfarova and Ladislav Maris: 2017 وتهدف إلى تطبيق نظام تكنولوجى حديث محاكاة للواقع، وتصميم وبرمجة نظام لدعم خدمات الإنقاذ والحرائق فى دي

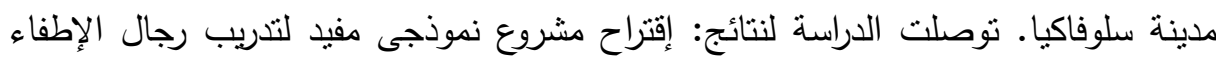

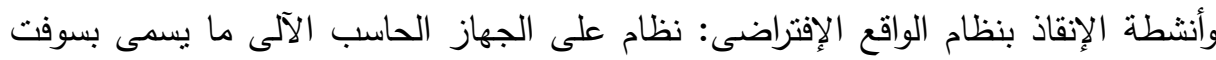
وير يحتوى على سيناريوهات التعامل، صورة من واقع حالة الطوارىه. دراسة أدهم هاني أبو النور( ع ا ـ Y): وتهدف إلى التعرف على كيفية التعامل مع الكوارث فى مصر، طبقا لنظام المؤسسات الحكومية للدولة ومعرفة ما هى المرحلة التى يتم فيها إجراءات التعامل مع الكوارث فى مصر قبل حدوث الكارثة أم بعد حدوثها. 
وتوصلت الدراسة إلى إجراءات الكوارث فى مصر بعد حدوث الكارثة حيث يوجد نقص

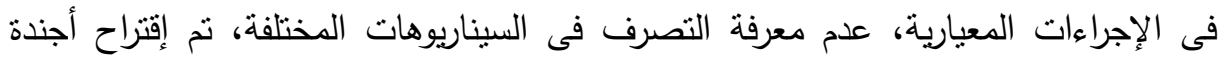
تصرفات للأنشطة المطلوبة مثل: إدارة الخسائر، إدارة الخطر، التحكم فى الأحداث، تقليل

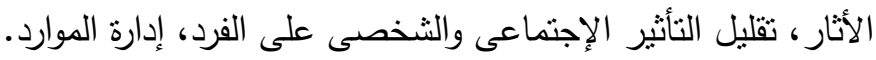
Ing-Marie Andersson; Kristina Gunnarsson; Gunner Rosen; دراسة Marie Mostrom Aerg (2014) الإتحادية فى مدينة السويد إلى تحديد المعرفة والخبرة للطلاب من سن 17 - ع ع على كيفية التعامل مع بيئة العمل الخطرة مستقبلا، تدريبهم على بيئة العمل قبل التخرج مما يساعدهم التعامل فى وظائفهز على الأزمات التى يتعرضون لها، وذللك بسبب كثرة عدد الوفيات

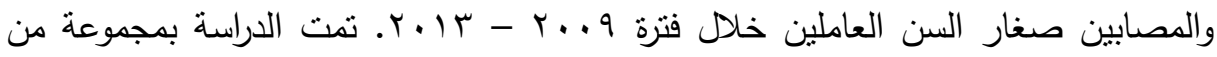

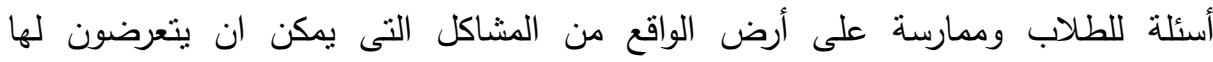

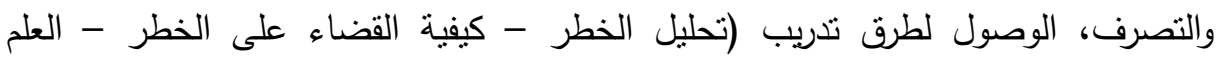
بالخطر المحتمل - منع الخطر) وضع خطة طويلة الأجل فى مواجهة الأزمات والأخطار للعمل المستقبلى للطلاب من أية حوادث، أخطار كيميائية وفيزيائية وأخطار إجنماعية متوقعة الجنه

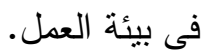
دراسة (2013) Jing Xin and Chongfu Huang وتهدف إلى التعرف على طرق الصين للتعامل مع الحرائق والتعرف على طرق لإدارة خطر الحرائق فى المبانى السكنية ومن

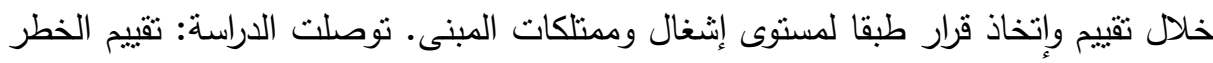
من خلال عدم الإستطاعة لإستمرارية العمل + خسارة فى الممنلكات، تحليل خطر الحرائق من خلال سيناريو الإطفاء الأولى للحريق، سيناريو سلوك الفرد، سيناريو السيطرة فى بداية

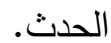

Julia Pingel; Cullen Case Jr.; Beth Amer; Raymond, A. دراسة Hornung and Alexander, H. (2012)

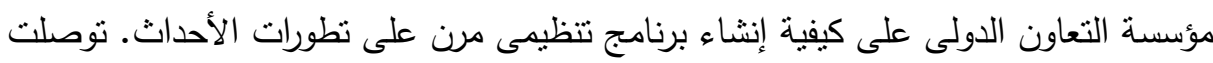

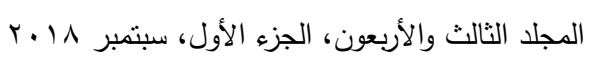


الدراسة لمنطلبات حتى تتم إستمرارية العمل والتعامل مع الأزمات حتى لا تتفاقم. ومن بعض فل

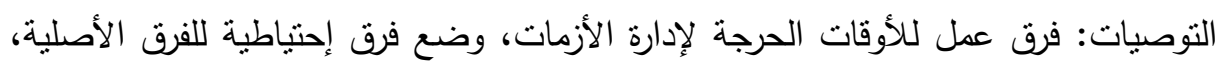
وثائق بديلة لخطط الطوارىء، تحديد المسئوليات والأسماء لفريق إدارة الأزمات والفريق البديل

Katerina Vichova; Martin Hromada and David Rehak (2017) دراسة وتهدف لعمل مقتزح خدمة إنقاذ الحرائق ودعم إتخاذ القرار أثناء حدوث الأزمة، إستخدام نظام محدد (معلومات إدارة الأزمات) لتسهيل عملية الإنقاذ والتعرف على تللك النظام وأبعاده. توصلت الدراسة: لنظام معلومات جغرافى عبارة عن خريطة للمكان ذات تقنية رقمية موحدة على المدى الطويل لجميع الأماكن: هو نظام للتعامل مع الأزمات بطريقة فعلية.

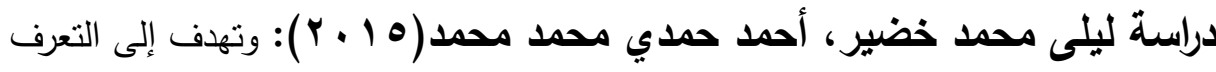
على الأخطار الرئيسية السبعة التى واجهت مصر فى الفترة السابقة وهى كالآتى: تقلب الأسعار؛ تغير فى الضرائب؛ تغير فى تكلفة الطاقة؛ السلامة؛ إضراب العاملين؛ تغييرات

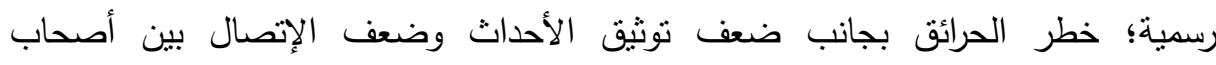

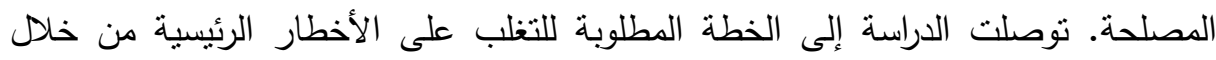
مصفوفة: التحديد والمعرفة + تحليل + توصيف ثم تحديد العوامل المؤثرة سواء كانت داخلية أم خارجية والتعرف على خطة الإستجابة من خلال (التجنب + القابلية والمرونة + التخفيف). دراسة Leif Jarle Gressgard (2014) وتهدف لتوضيح دور الإدارة الكفء للمعرفة

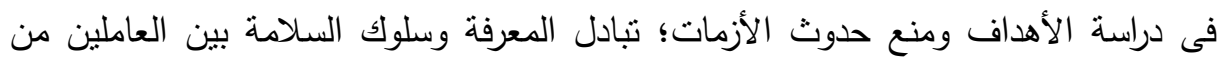

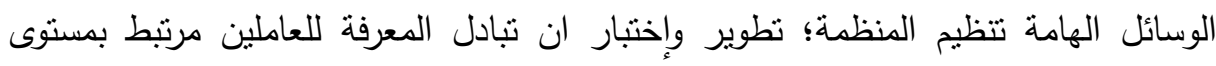

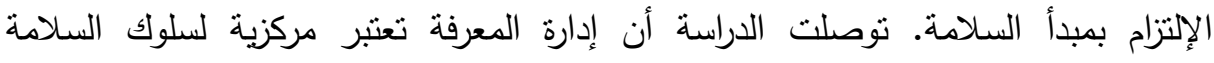

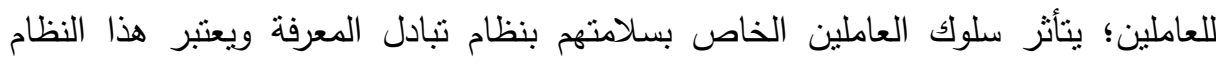
المستخدم من وسائل القوية لتوقع الأخطار للعاملين.

Nik Nadian Nisa Nik Nazli; Sapora Sipon; Abdul Rahim دراسة. Zumrah and Salhah Abdullah (2015)

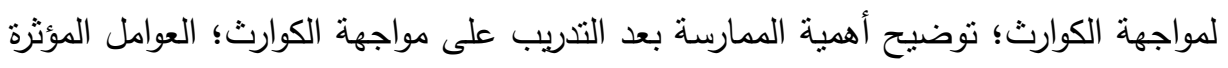
490

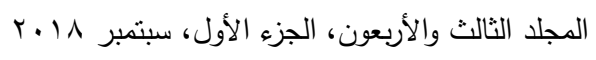


على عملية التدريب. توصلت الدراسة: يلعب دور التحضير للتنريب على مواجهة الكوارث

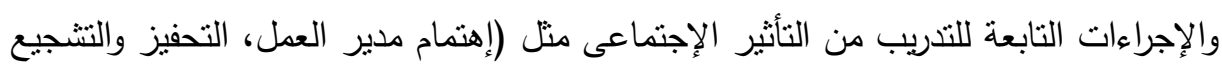

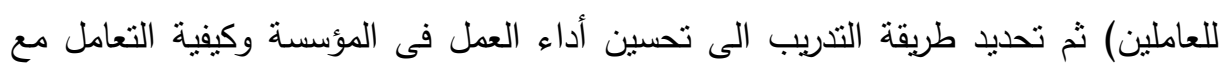

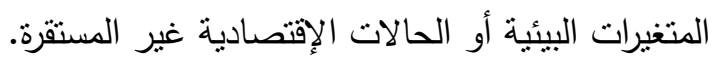

Olufunsho Awodele; Temidayo, D. Popoola; Akin Akinyede دراسة

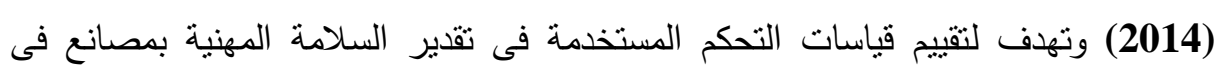

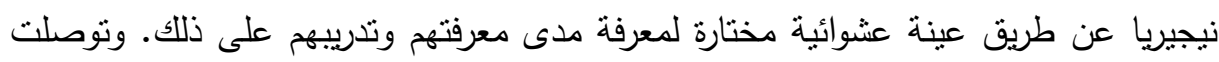
الدراسة إلى نتيجة عامة: التوصل الى الإحتياج الى تطوير فعالية إطار العمل بطريقة آمنة

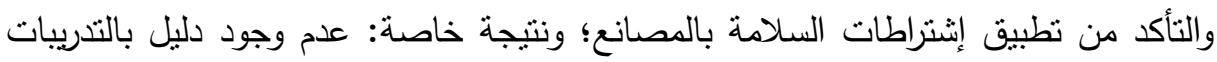

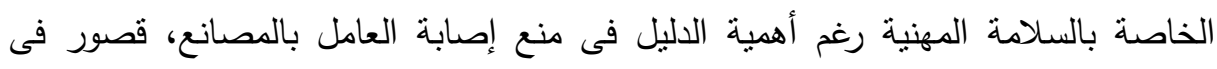
قياسات التدريب على المخاطر السلامة المهنية. دراسة Runjiao Liu; Difei Jiang and Lei Shi (2016) وتهدف لربط تخطيط وتصميم الحجرات الدراسة بكفاءة الإخلاء وقواعد التصرف للطلاب، توضيح قواعد التصرف لتهاء

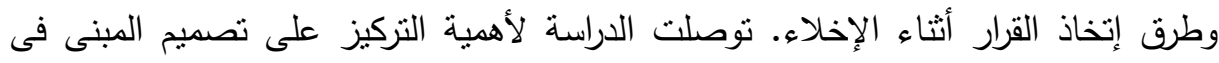

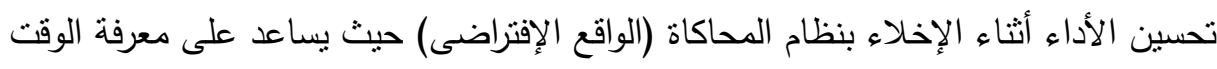
للإخلاء وطرق تصرف الطلاب.

Sarah Moreira Bernardes; Francisco Rebelo; Etisangela vilar دراسة وطرف Paulo Noriega and Tania Borges (2015)

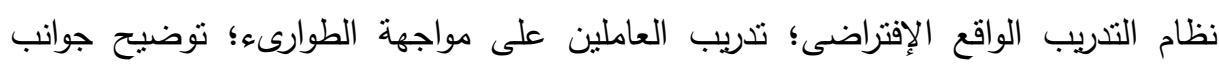

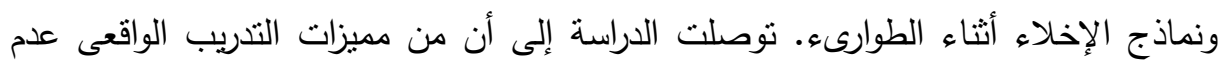

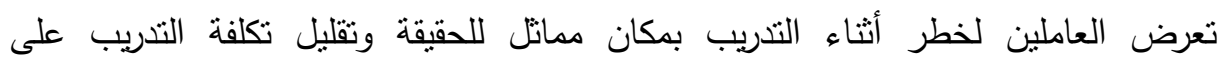
الطوارى؛ إستجابة فعالة للأشخاص عند حدوث الطوارىء بسبب التدريب خارج المنشأة يعطى مصداقية عند سماع إنذار الطوارىء الحقيقى. 
Sarah-Louise Donovan; Paul, M. Salmon and Micheal, G. دراسةة وتهدف إلى الإلتزام بالقرارات والأعمال المطلوبة لفريق قيادة شئون Lenne (2015)

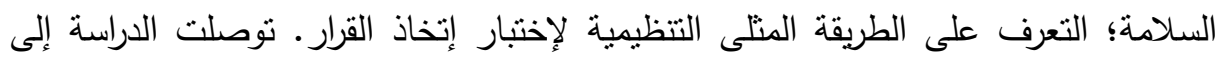

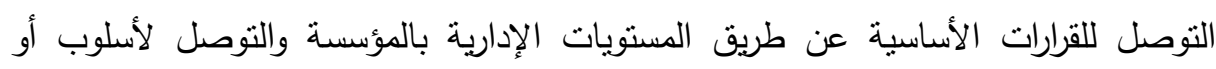

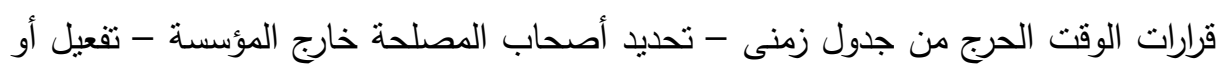
تحديد دور تحركات المؤسسة. Shaharam Mahoudi; Fakhradin Ghasemi; Iraj Mohammad دراسة fam and Esamaeil Soleimani (2014) وتحسين الصحة والسلامة المهنية بطريقة مستمرة من خلال التعرف على أنظمة. نوصلت

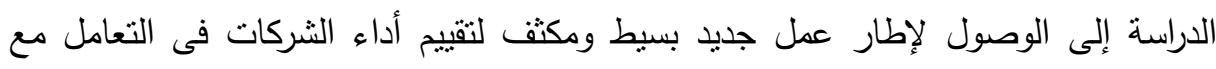

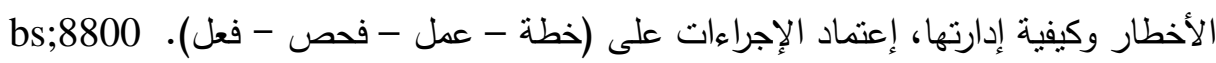
,ohsas 18001

دراسة Terje Aven and Bodil, S. Krohn (2014) وتهدف لوضع أجندة إرشاد بطريق تفكير وطرق جديدة لإدارة الأحداث المفاجئة من خلال مبدأ اليقظة والجودة فى لى لئح

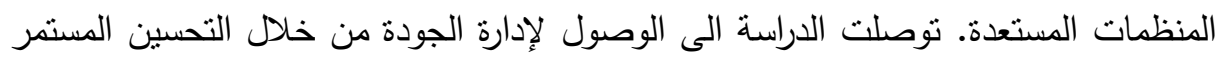

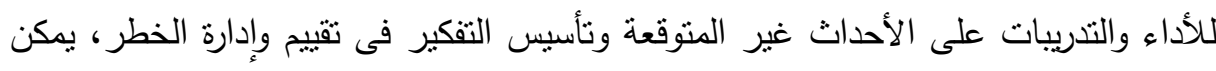

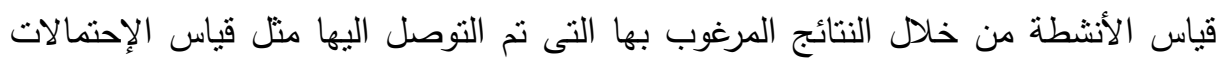

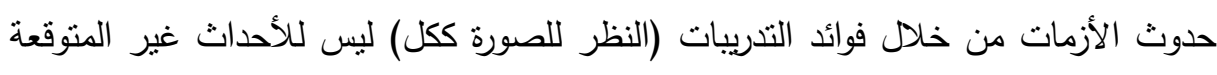
فقط ولكن للنتائج المرغوب فيها أيضا.

\section{الإطار اللنظاره}

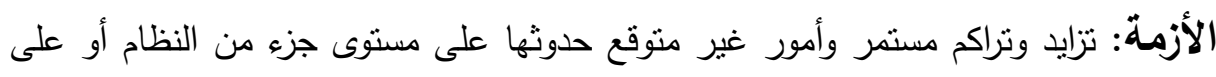
مستوى النظام بأكمله. (دراسة ندا، 0 ا • ب). إدارة الأزمة: هو إتخاذ مجموعة من الأعمال والأنشطة التصحيحية فى جميع مراحل الأزمة

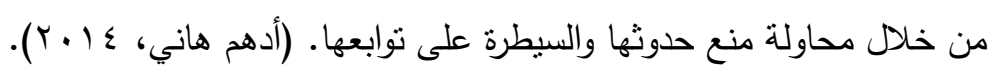


الأزمة الأمنية: هو حدث خارجى سلبى غير منوقع من حيث الزمان والنوع وكذللك لا يمكن معرفة نتائجه يؤثز على أمن المؤسسة ويعرقل عملها مما يظهر الخلل الأمنى الداخلى لألى

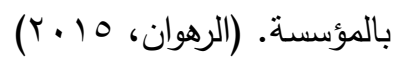
الأزمة البيئية: هو ظرف يحدث نتيجة ظاهرة بيئية طبيعية أم بشرية تؤدى إلى خسائر مادية

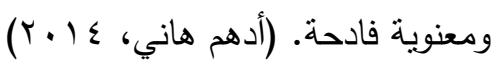
هذه مجموعة من الأزمات البيئية والأمنية:

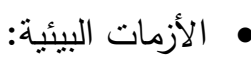

- أزمة بيئية طبيعية: زلزال، سيول، فيضان، إنهيار جزئى أم كلى للمبنى (عمر إفتراضى)، حرائق بسبب إرتفاع درجة الحرارة. - أزمة بيئية من صنع الإنسان: الحريق بسبب التبار الكهربائي - تسريب غاز طبئ طبيعى، أزمات تكنولوجية، إنفجار بسبب المرافق (الكهباء - شبكة المياه - شبكة الغاز - شبكة

• أزمات أمنية تعرقل عمل المؤسسة: إنفجار، هجوم ارهابي، هجوم مسلح بغرض السرقة.

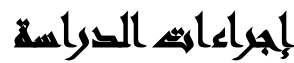

تألفت عينة الدراسة من: العينة الاستطلاعيةة: أجريت هذه الدراسة الاسنطلاعية على عينة مكونة من ( •ـ) فرد من أجل الإجابة على (•؛) استبيان نم إرجاعها كاملة، للتأكد من صدق وثنات الإنهات الاختبار الاستنيان.

أداة القياس: اعتمدنا في دراستتا الحالية على الاستبيان كأداة من أدوات جمع البيانات حول

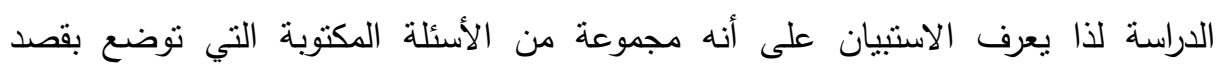
الحصول على معلومات وآراء المبحوثين حول ظاهرة أوموضوع معين ومن أهم ما تتميز به الهيه الاستبانة هونوفير الكثير من الوقت والجهد على الباحث، وعلى هذا الأساس تم تصميم 
استبيان خاص بموضوع الدراسة مصمم من قبل الباحث وذللك من أجل جمع البيانات والمعلومات الخاصة بموضع الدراسة. ويتكون هذا الاستبيان من ثلاث أجزاء، الجزء الأول يتضمن البيانات الثخصية، والجزء

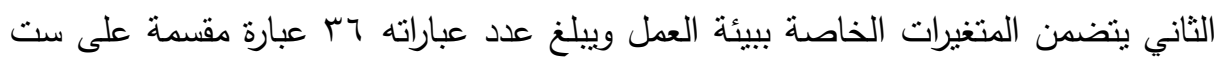
أبعاد، والجزء الثالث يتضمن البنود الخاصة بمسنوى كفاءة أداء العاملين وييلغ عدد عباراته . 1 عبارة. أما البدائل التي تم استعمالها في كلا الثقين فهي بدائل واحدة وهيه بدائل: موافق بثندة، موافق، محايد، غير موافق، غير موافق بشدة. وسنتطرق إلى كيفية حساب كل خاصية من هاتين الخاصيتين.

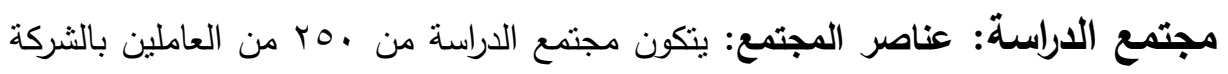
المصرية للاتصالات بالقرية الذكية. اختيار العينة: وقد قام الباحث بالاعتماد على أسلوب العينة العشوائية في تحديد مفردات الدراسة لمراعاة أن يناح لكل فرد من مفردات مجتمع البحث نفس الفرص المتكافئة للاختيار

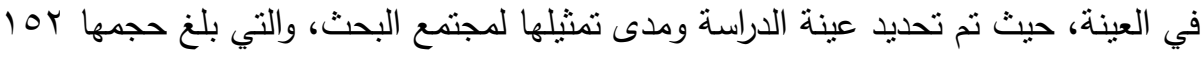
العينة الفعلية: بعد التحقق من صدق أداة القياس وثباتها، وزعت الاستبانات على أفراد عينة

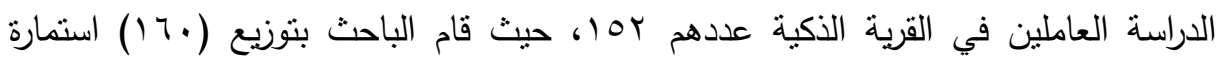
تحسباً لوجود استمارات غير مسترجعة وغير صالحة للتحليل الاحصاء، وبلغ عدد المسترجع منها (107) استمارة، منهم (^) استمارات غير صالحة للتحليل الإحصائي، وبالتالي تكونت

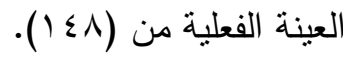
نتائج الصدق التمييزي: وثبات الاستبيان من خلال نطبيقه على عينة استطلاعية مكونة

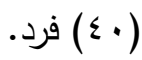
لحساب القوة التمييزية رتبت الدرجات الكلية التي حصل عليها من أفراد العينة الاستطلاعية بعد التصحيح ترتيباً تصاعديا من أقل درجة إلي أعلي درجة، وأخذت أدني (\%rv) 
وأطلق عليها (المجموعة العليا)، وقد اعتمد الباحث على طريقة المجموعنين المتطرفتين، والجدول رقم (1) يوضح نتائج هذا الإجراء. جدول(1) (1) نتائج الصدق التمبيزي

\begin{tabular}{|c|c|c|c|c|c|c|c|}
\hline الاستدلال & دلالة Tستوي & قيمة t & الحرية Df & الانحراف & المتوسط & العدد & المستويات \\
\hline \multirow{2}{*}{ دالة } & \multirow{2}{*}{$\cdot, \cdots$} & \multirow{2}{*}{ גו, } & \multirow{2}{*}{$r}$. & ו & $r, q \cdot v)$ & 11 & $\begin{array}{c}\text { المجموعة العلي \% \% } \\
\% \text { \% }\end{array}$ \\
\hline & & & & هT, T., & $r, \Lambda \cdot \wedge r$ & 11 & 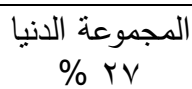 \\
\hline
\end{tabular}

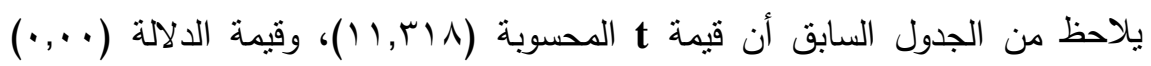
وهي دالة عند ا +, •، مما يثبر إلى أن للمقياس قدرة على التمبيز بين طرفيه. الصدق البنائي: - n جدول(ץ): نتائج الصدق البنائي من خلال معامل ارتباط أبعاد الاستبيان بمجموع الدرجة

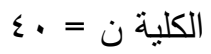

\begin{tabular}{|c|c|c|c|}
\hline الارتباط & \multicolumn{2}{|c|}{ أبعاد الاستبيان } & م \\
\hline$(* *) \cdot, \wedge 91$ & معامل ارتباط بيرسون & \multirow{2}{*}{ الاتصالات } & 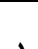 \\
\hline$\cdot, \cdot 1$ & الدلالة المعنوية & & 1 \\
\hline$(* *) \cdot, \wedge 9 \wedge$ & معامل ارتباط بيرسون & \multirow{2}{*}{ مبادرة التدريب التنظيمي والمكتسب } & \multirow{2}{*}{ r } \\
\hline$\cdot, \cdot 1$ & الدلالة المعنوية & & \\
\hline$(* *) \cdot 97 \pi$ & معامل ارتباط بيرسون & \multirow{2}{*}{ الإجراءات الفعالة } & \multirow{2}{*}{$r$} \\
\hline$\cdot, \cdot 1$ & الدلالة المعنوية & & \\
\hline$(* *) \cdot$ * Атr & معامل ارتباط بيرسون & \multirow{2}{*}{ الرقابة } & \multirow{2}{*}{$\varepsilon$} \\
\hline$\cdot, \cdot 1$ & الدلالة المعنوية & & \\
\hline$(* *) \cdot, 9 \cdot 1$ & معامل ارتباط بيرسون & \multirow{2}{*}{ العرض والمراجعة } & \multirow{2}{*}{0} \\
\hline$\cdot, \cdot 1$ & الدلالة المعنوية & & \\
\hline$(* *) \cdot, \wedge 9 Y$ & معامل ارتباط بيرسون & \multirow{2}{*}{ الرصد والنطبيق } & \multirow{2}{*}{7} \\
\hline$\cdot, \cdot 1$ & الدلالة المعنوية & & \\
\hline$(* *) \cdot, \Lambda) \Gamma$ & معامل ارتباط بيرسون & \multirow{2}{*}{ مستوى كفاءة أداء العاملين } & \multirow{2}{*}{ V } \\
\hline$\cdot, \cdot 1$ & الدلالة المعنوية & & \\
\hline
\end{tabular}

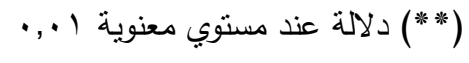

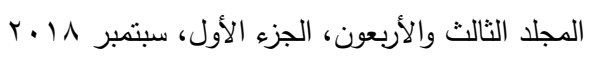


يتضح من الجدول أن جميع الأبعاد ترتبط ببعضها البعض بالدرجة الكلية وهي ذو دلالة

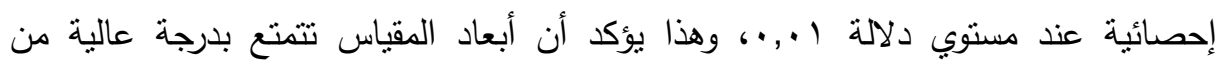

ثبات الاستبيان: تحقق الباحث من ثبات استبيان الدراسة من خلال طريقتين وهما طريقة التجزئة النصفية ومعامل ألفا كرونباخ. أولاً: طريقة التجزئة النصفية: Split-Half Coefficient method نم استخدام درجات العينة الاسنطلاعية لحساب ثنات الاستبيان بطريقة التجزئة النصفية، حيث احتسبت درجة النصف الأول لكل بعد من أبعاد الاستبيان وكذلك درجة النصف الثاني من الدرجات وذلك لحساب معامل الارتباط بين النصفين ثم جري تعديل الطول باستخدام معادلة سبيرمان وبراون النصفية المنساوية (Spearman-Brown Coefficient)، ومعادلة جنمان للتجزئة النصفية غير المنساوية (Guttman Split-Half Coefficient) والجدول يوضح ذللك.

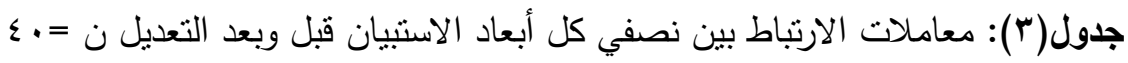

\begin{tabular}{|c|c|c|c|c|}
\hline معامل الثبات بعد & الارتباط قبل & عدد العبارات & الأبعاد & s \\
\hline •,人тr & $\cdot, \vee \vee 09$ & $\varepsilon$ & الاتصالات. & 1 \\
\hline$\cdot, \wedge 70$ & $\cdot, \wedge r r$ & v & مبادرة التدريب التنظيمي & r \\
\hline$\cdot, 9 \wedge \vee$ & $\cdot, 9 \vee \mu$ & $1 \pi$ & الإجراءات الفعالة. & $r$ \\
\hline., $90 Y$ & $\cdot, 9 \cdot 1$ & $\varepsilon$ & الرقابة. & $\varepsilon$ \\
\hline$\cdot, \wedge r \wedge$ & $\cdot, V \cdot Y$ & $\varepsilon$ & العرض والمراجعة. & 0 \\
\hline$\cdot, 9 \leqslant V$ & $\cdot, \wedge 99$ & $\varepsilon$ & الرصد والتطبيق. & 7 \\
\hline$\cdot, 9 \leq 7$ & $\cdot, \wedge 9 \vee$ & 1. & مستوى كفاءة أداء العاملين. & $\mathrm{V}$ \\
\hline$\cdot, \wedge \wedge \wedge$ & $\cdot, \vee \vee १ \wedge$ & $\varepsilon\rceil$ & إجمالى أبعاد الاسنتيان & \\
\hline
\end{tabular}

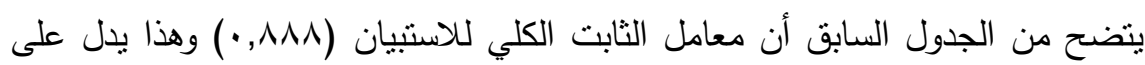
أن ابعاد المقياس تتمتع بدرجة عالية جدا من الثبات بطمئن الباحث إلى تطبيقه على عينة الدراسة. ثانيا: طريقة ألفا كرونباخ Alpha Cronbach استخدم الباحث طريقة أخري من طرق

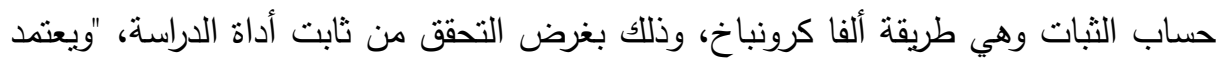


ألفا كرونباخ على حساب تباينات الفقرات وتباين الاختبار، وعلى الرغم من أن قواعد القياس

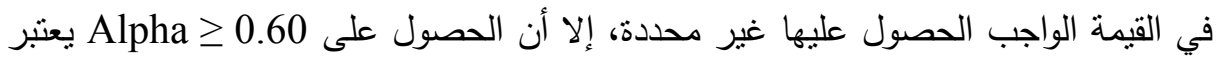
معقولا، والجدول يوضح ثبات أبعاد المقياس باستخدام ألفا كرونباخ.

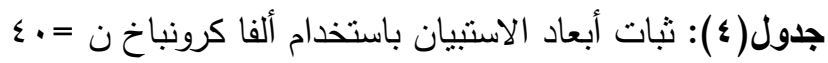

\begin{tabular}{|c|c|c|c|}
\hline معامل ألفا كرونباخ & عدد العبارات & الأبعاد & ? \\
\hline$\cdot, 9 \cdot 1$ & $\varepsilon$ & الاتصالات. & 1 \\
\hline$\cdot, 91 \leq$ & $\mathrm{V}$ & مبادرة التذريب التتظيمي والمكتسب. & $r$ \\
\hline$\cdot, 9 \Lambda$. & 15 & الإجراءات الفعالة. & r \\
\hline$\cdot, 941$ & $\varepsilon$ & الرقابة. & $\varepsilon$ \\
\hline$\cdot, \vee \vee$. & $\varepsilon$ & العرض والمراجعة. & 0 \\
\hline$\cdot, 9 \leq 7$ & $\varepsilon$ & الرصد والنطبيق. & 7 \\
\hline$\cdot, 9 \leqslant r$ & 1. & مستوى كفاءة أداء العاملين. & $\mathrm{V}$ \\
\hline$\cdot, 979$ & $\leqslant 7$ & إجمالي ابعاد الاستبيان & \\
\hline
\end{tabular}

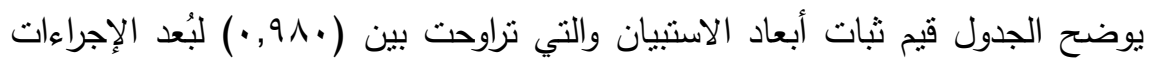

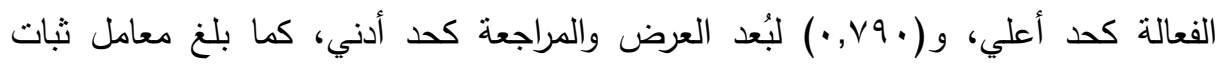
إجمالي المقياس (979, ·)، وتدل مؤشرات ألفا كرونباخ أعلاه على تمتع أبعاد الاستبيان بمعامل ثابت عالٍ وبقدرتها على تحقيق أغراض الدراسة، ويطمئن الباحث لتطبيقه على عينة

\section{أساليب المعالجة الْإحصائية المستخدِمة فِي الدّراسة:}

• المتوسطات الحسابية والانحرافات المعيارية والمتوسط المئوي المرجح في نتائج التحليل

$$
\text { الوصفي للمتغيرات. }
$$

ه تحليل الانحدار الخطي البسط Simple Linear Regression Analysis لمعرفة أثز

$$
\text { كل بُعد من أبعاد (المتغير المستقل) على (المتغير التابع). }
$$

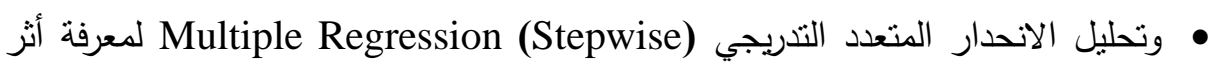

$$
\text { أبعاد (المتغير المستقل) على (المتغير التابع). }
$$


• تم استخدام (Independent Samples T-test) للعينتين المستقلتين لاختبار الفروق الني تعزى لـتغير النوع. • تم استخدام اختبار تحليل التباين الأحادي (One way ANOVA) لاختبار الفروق.

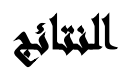

الفرضية الرئيسية الأولى: "يوجد علاقة أثر ذات دلالة احصائية لبيئة العمل بأبعها المختلفة على مستوى كفاءة أداء العاملين".

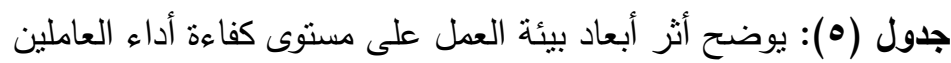

\begin{tabular}{|c|c|c|c|c|c|c|}
\hline الدلالة مستوي & قيمة T & مستوي & قيمة F & التراكمي R2 التحديد & $\begin{array}{c}\text { الارتباط } \\
\text { (R) }\end{array}$ & أبعاد المحاسبة عن \\
\hline$\cdot, \cdots$ & $0, V \leqslant V$ & $\cdot, \cdots$ & $\neg \wedge 1, \leq M$ & $\cdot, \wedge Y \Sigma$ & $\cdot, 9 \cdot v$ & الإجراءات الفعالة \\
\hline$\cdot, \cdots$ & $1 \cdot, \cdot r \leq$ & $\cdot, \cdots$ & $90 \%, \Sigma \wedge \wedge$ &., $9 \times 9$ & $\cdot, 97 \leq$ & الرصد والتطبيق \\
\hline$\cdot, \cdots 1$ & r, YVA & $\cdot, \cdots$ & $1 \vee 0,979$ & $\cdot, 9 \leq \wedge$ & $\cdot, 9 \vee \leqslant$ & الاتصالات \\
\hline & $r, q \leq \wedge$ & $\cdot, \cdots$ & זדזיט & $\cdot, 90 \leqslant$ & $\cdot, 9 \vee \vee$ & التظظيمي والمكتسب التدريب \\
\hline$\cdot, \cdots 1$ & $r, Y \backslash \Sigma$ & $\cdot, \cdots$ & $7 \pi \leq, 7 \vee 0$ & $\cdot, 90 \mathrm{~V}$ & $\cdot, 9 \vee \wedge$ & الرقابة \\
\hline$\cdot, \cdot 17$ & $r, \varepsilon Y q$ & $\cdot, \cdots$ & $0 \leq \Lambda, 1\} 0$ & $\cdot, 909$ & $\cdot, 9 \vee 9$ & العرض والمراجعة \\
\hline
\end{tabular}

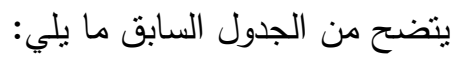

- دخول أبعاد بيئة العمل (المتغير المستقل) في معادلة الانحدار، أن بُعد (الإجراءات

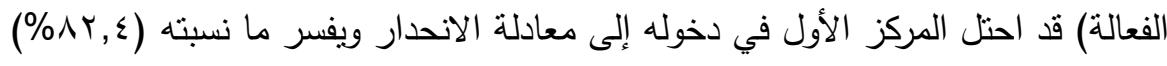

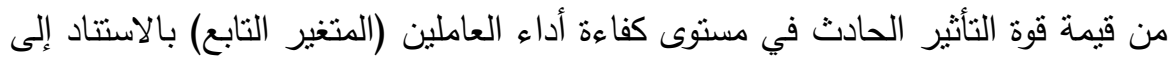

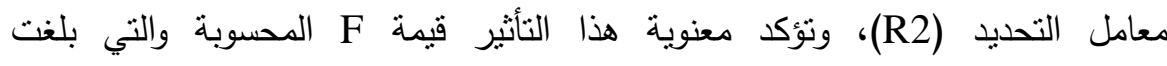

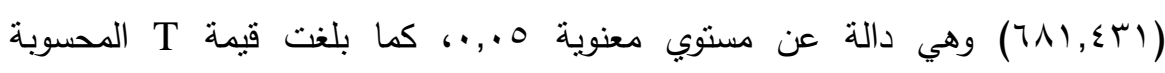
(0,V V V V)

- يلي ذلك بُعد (الرصد والتطبيق) الذي فسر مع بُعبد (الإجراءات الفعالة) ما نسبته

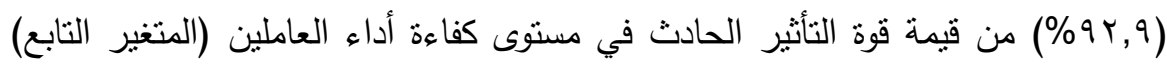

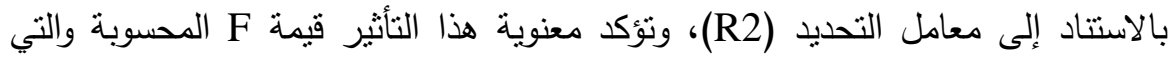




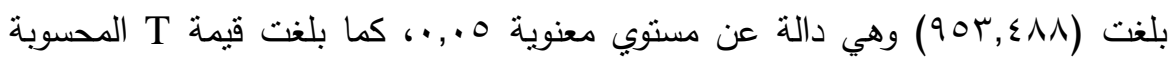

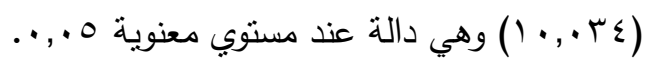

- يلي ذللك بُعد (الاتصالات) الذي فسر مع كل من بُعدي (والرصد والتطبيق، والإجراءات

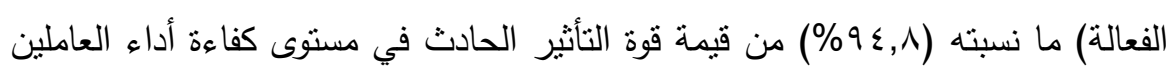

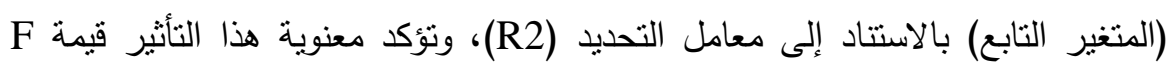

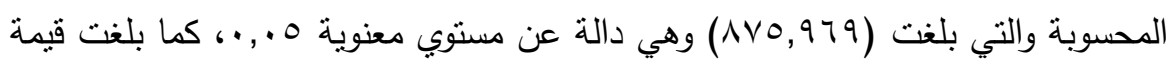

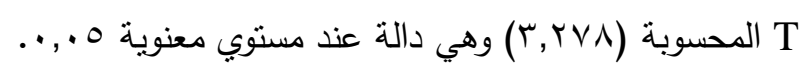
- يلي ذللك بُعد (مبادرة التدريب التنظيمي والمكتسب) الذي فسر مع كل من من (الاتصالات،

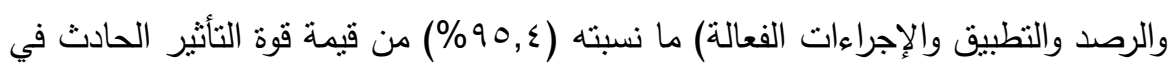
مستوى كفاءة أداء العاملين (المتغير التابع) بالاستتاد إلى معامل التحديد (R2)، وتؤكد

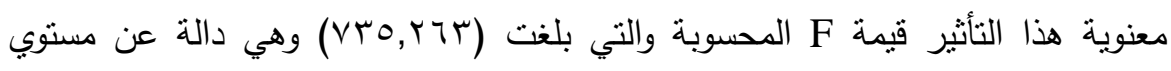

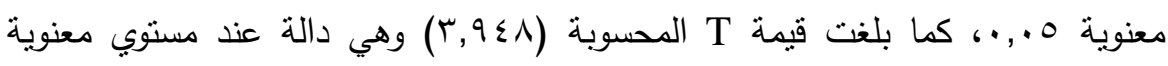
$\therefore, .0$

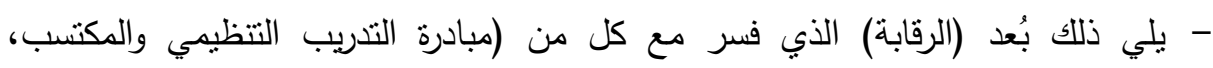

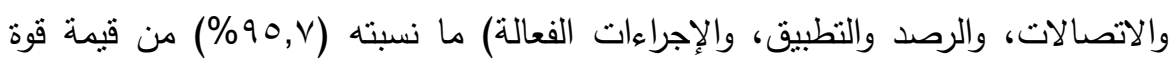

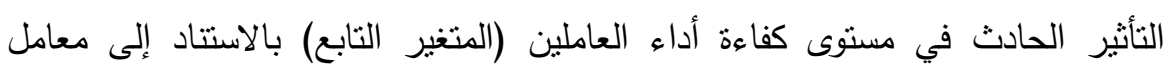

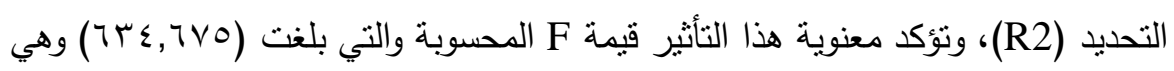

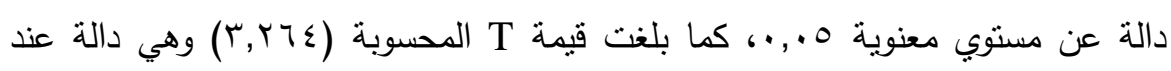

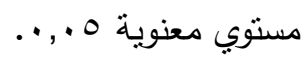
- يلي ذللك بُعد (العرض والمراجعة) الذي فسر مع كل من (الرقابة، مبادرة التدريب التنظيمي

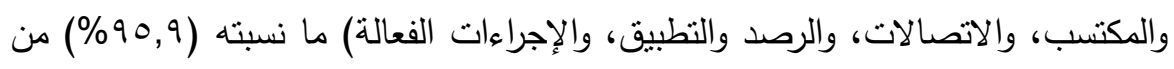

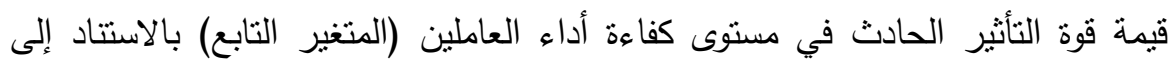
معامل التحديد (R2)، وتؤكد معنوية هذا التأثير قيمة F المحسوبة والتي بلغت 


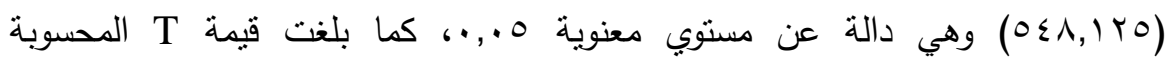

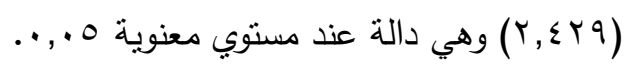

تفسير اختبار الفرضية: وهذا يعني أن أبعاد بيئة العمل مجتمعة معا، تدل هله على أن التغير

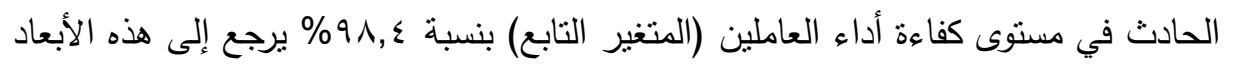
مجتمعة معاً، وأن ا,ء\% التغيرات الحادثة في مستوى كفاءة أداء العاملين (المتغير التابع) ترجع إلى الخطأ العشوائي أو عوامل أخري.

وبناء على ما نقام فأننا نقبل الفرضية الرئيسية الاولي التي تتص أتصلي على أنه: يوجد علاقة أثز ذات دلالة احصائية لبيئة العمل بأبعدها المختلفة على مستوى كفاءة أداء العاملين. الفرضية الثانية: "توجد فروق ذات دلالة إحصائية في استجابات المستقصي منهم حول أبعاد بيئة العمل تبعاً للمتغيرات الثالية (النوع، العمر ، المؤهل العلمي)".

بلنسبة لمتغير النوع: Independent Samples T-test قام الباحث باستخدام T-Test جدول(†): نتائج اختبار الفروق في استجابات عينة الدراسة حسب متغير النوع

\begin{tabular}{|c|c|c|c|c|c|c|c|}
\hline مستوي & قالدلة & قيمة "ت" & \multicolumn{2}{|c|}{ إناث (ن= צ ه) } & \multicolumn{2}{|c|}{ ذكور (ن= r a } & المتغيرات \\
\hline غالة & $\cdot, r \leqslant \wedge$ & $\cdot, 9 Y \leq$ & 10,17 & $10 \cdot, 1$ & $1 r, \wedge \Lambda$ & 10r, \&. & اجمالي أبعاد \\
\hline
\end{tabular}

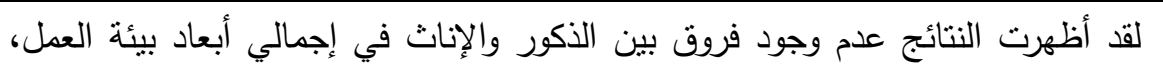

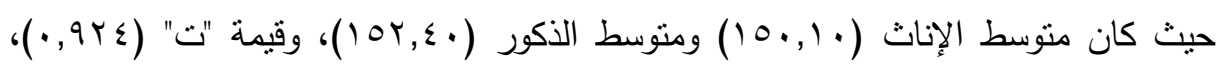
كما أن قيمة دلالة الإختبار المحسوبة للتحقق من وجود فروق جوهرية بين الذكور والإناث

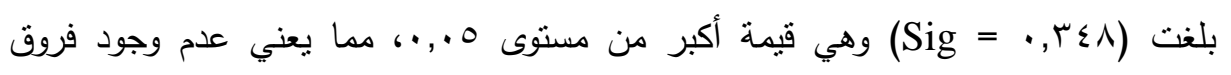

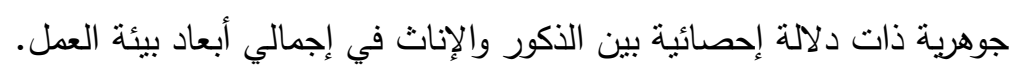


بالنسبة لمتغير العمر: قام الباحث باستخدام (One way ANOVA).

\begin{tabular}{|c|c|c|c|c|c|c|}
\hline قالاليمة & قيمة & الانحراف & المتوسط & ن العدد & العمر & المتغيرات \\
\hline \multirow{4}{*}{ •, $\leqslant T V$} & \multirow{4}{*}{$\cdot, 911$} & $|r, V r r q|$ & $101, \varepsilon Y \leqslant Y$ & "r & أقل من ·r سنة & \multirow{4}{*}{ أبعاد بيئة } \\
\hline & & $1 \varepsilon, \varepsilon r \| \mid T$ & $101,079$. & 01 & 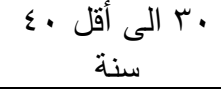 & \\
\hline & & $10, .0 V \cdot \varepsilon$ & 1OT, YVTV & $\varepsilon \varepsilon$ & • • - الى أقل & \\
\hline & & $10, \Lambda \mid V \leqslant V$ & $1 \leqslant 0, V 79 Y$ & $\pi$ & أكثر من .0 سنة & \\
\hline
\end{tabular}

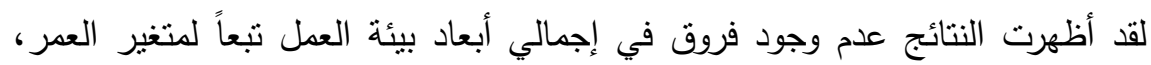

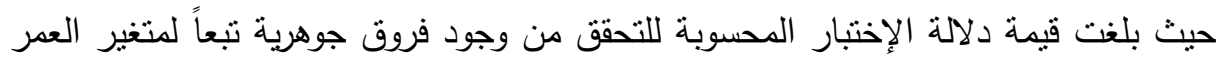

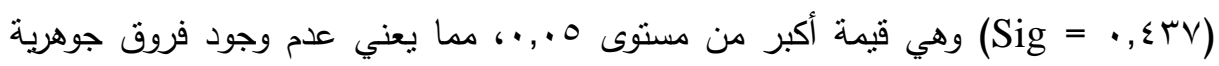

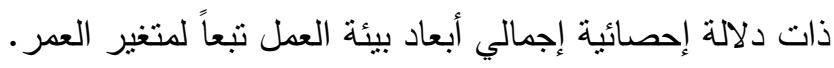
بالنسبة لمتغير المؤهل العلمي: قام الباحث باستخدام (One way ANOVA).

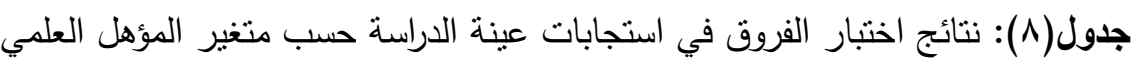

\begin{tabular}{|c|c|c|c|c|c|c|}
\hline قالدلالة & $\begin{array}{l}\text { قيمة } \\
\text { "f" }\end{array}$ & الانعياري & المتوسط & ن العداد 1 ا & المؤهل العلمي & المتغيرات \\
\hline \multirow{4}{*}{ • } & \multirow{4}{*}{$\cdot, \wedge \wedge\rangle$} & $1 r, 0 \cdot \vee \vee q$ & IOY,rOVI & $r \wedge$ & دبلوم & \multirow{4}{*}{ بيئة التملي أبعاد } \\
\hline & & $10,991 \wedge \leq 9$ & $1 \leq \vee, \varepsilon \wedge 10$ & TV & ليسانس & \\
\hline & & $1 \varepsilon, .01 V 1$ & $10 r, 09 \leqslant r$ & 79 & بكالوريوس & \\
\hline & & $1 \leqslant, \varepsilon O Y \cdot V$ & אזה., & $T \varepsilon$ & دراسات عليا & \\
\hline
\end{tabular}

لقد أظهرت النتائج عدم وجود فروق في إجمالي أبعاد بيئة العمل تبعاً لمتغير المؤهل العلمي، حيث بلغت قيمة دلالة الإختبار المحسوبة للتحقق من وجود فروق فئون جوهرية تبعاد

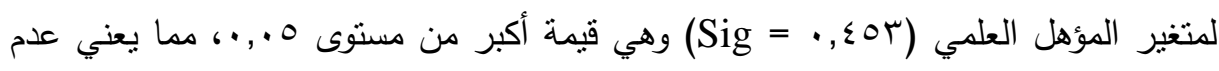
وجود فروق جوهرية ذات دلالة إحصائية إجمالي أبعاد بيئة العمل تبعاً لمتغير المؤهل العلمي.

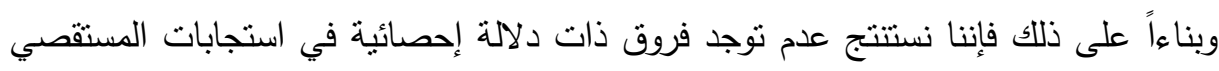
منهم حول أبعاد بيئة العمل تبعاً لمتغيرات (النوع، العمر ، المؤهل العلمي). 
الفرض الفرعي الأول: يوجد علاقة أثز ذات دلالة احصائية لبُعد الاتصالات على مستوى

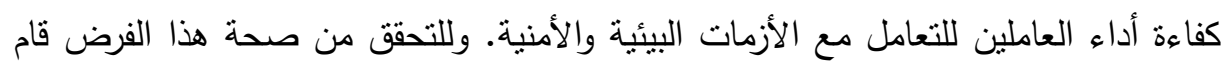
الباحث باستخدام الانحدار الخطي البسيط. جدول(9): نتائج تحليل الانحدار الخطي البسيط لتأثير بُعد الاتصالات على مستوى كفاءة الباء أداء العاملين

\begin{tabular}{|c|c|c|c|c|c|c|c|c|}
\hline مستوي الدلالة & المحسوية & 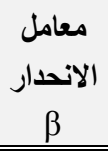 & درجات & مستوي & المحسوية & 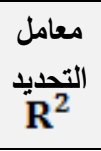 & $\begin{array}{c}\text { الارتباط } \\
\text { (R) }\end{array}$ & المتغير \\
\hline \multirow{3}{*}{$\cdot, \cdots$} & \multirow{3}{*}{$17,7 \wedge 7$} & \multirow{3}{*}{ T,YTY } & 1 & \multirow{3}{*}{$\cdot, \cdots$} & \multirow{3}{*}{$r \vee \wedge, r \leq r$} & \multirow{3}{*}{$\cdot, 707$} & \multirow{3}{*}{$\cdot, \wedge)$. } & \multirow{3}{*}{ الاتصالات } \\
\hline & & & $1 \leq 7$ & & & & & \\
\hline & & & $1 \leq V$ & & & & & \\
\hline
\end{tabular}

يوضح الجدول تأثثر بُعد الاتصالات على مستوى كفاءة أداء العاملين، إذ أظهرت نتائج التحليل الإحصائي وجود تأثير ذو دلالة إحصائية لبُعد الاتصالات على الأصلى مستوى كفاءة أداء

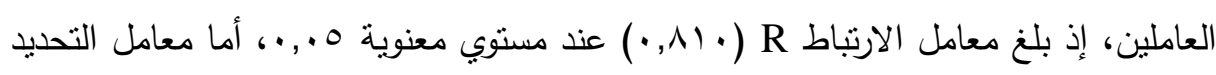

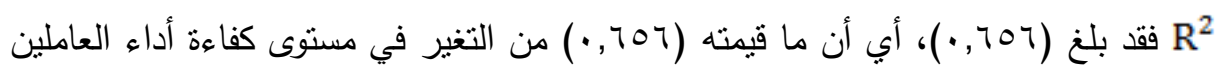

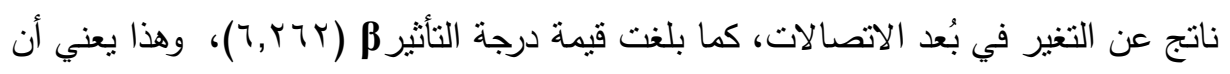

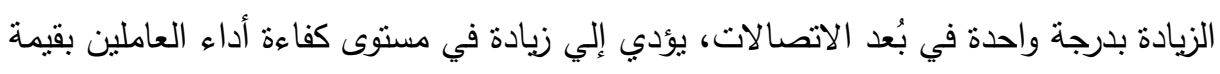

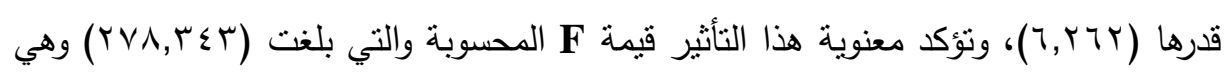

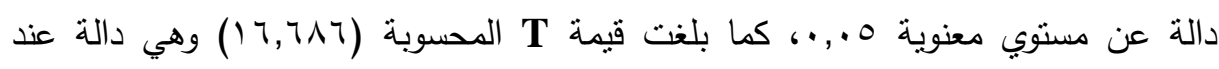

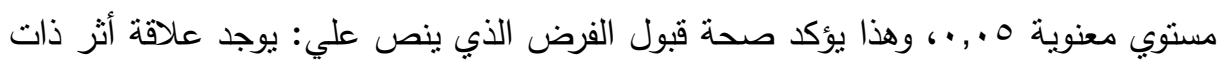

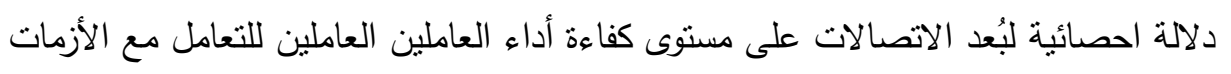
البيئية والأمنية. الفرض الفرعي الثاني: "توجد علاقة أثز ذات دلالة احصائية لبُعد مبادرة التنريب التنظيمي والمكتسب على مسنوى كفاءة أداء العاملين العاملين للتعامل مع الأزمات البيئية والأمنية". وللتحقق من صحة هذا الفرض قام الباحث باستخدام الانحدار الخطي البسيط. 
جدول(• (1): نتائج تحليل الانحدار الخطي البسيط لتأثير بُعد مبادرة التدريب التنظيمي والمكتسب على مستوى كفاءة أداء العاملين

\begin{tabular}{|c|c|c|c|c|c|c|c|c|}
\hline مستوي & المحسوية & الانحدار & $\begin{array}{l}\text { الحرية } \\
\text { DF } \\
\end{array}$ & مستوي & المحسوية & $\begin{array}{l}\text { التحديد } \\
\text { معامل }\end{array}$ & $\begin{array}{c}\text { الارتباط } \\
\text { (R) }\end{array}$ & المتغير \\
\hline \multirow{3}{*}{$\cdot, \cdots$} & \multirow{3}{*}{$r O, r \cdot V$} & \multirow{3}{*}{$7, Y \wedge 0$} & 1 & \multirow{3}{*}{$\cdot, \cdots$} & \multirow{3}{*}{$T \varepsilon \cdot, \varepsilon \leqslant \varepsilon$} & \multirow{3}{*}{ • } & \multirow{3}{*}{$\cdot, q \cdot r$} & \multirow{3}{*}{ التنتباديب } \\
\hline & & & $1 \leqslant 7$ & & & & & \\
\hline & & & $1 \leqslant V$ & & & & & \\
\hline
\end{tabular}

يوضح الجدول نأثثر بُعد مبادرة التدريب التتظيمي والمكتسب على مستوى كفاءة أداء العاملين، إذ أظهرت نتائج التحليل الإحصائي وجود تأثثير ذو دلائلة إحصائية لبُعد مبادرة

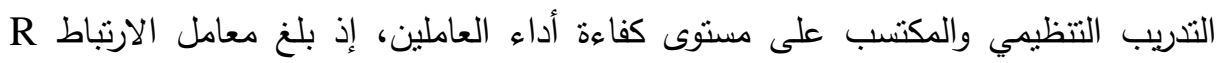

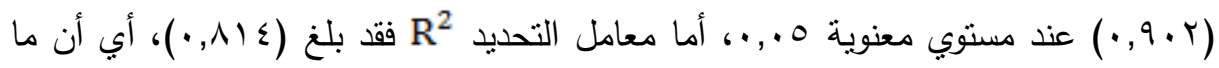
قيمته (ع (N, ·) من التغير في مستوى كفاءة أداء العاملين ناتج عن التغير في بُعد مبادرة

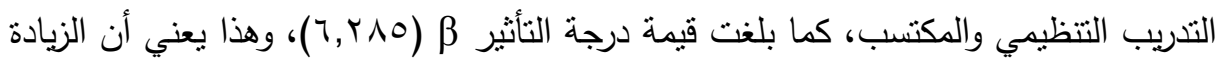
بدرجة واحدة في بُعد مبادرة التدريب التنظيمي والمكتسب، يؤدي إلي زيادة في مستوى كفاءة

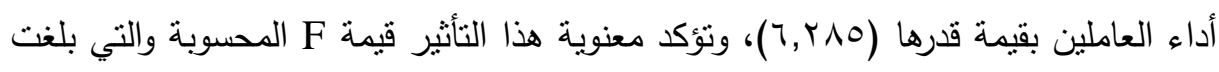

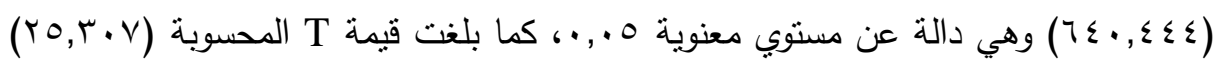

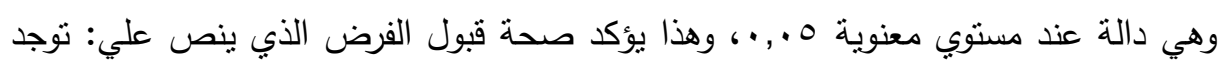
علاقة أثر ذات دلالة احصائية لبُعد مبادرة التدريب التتظيمي والمكتسب على ولى مستوى كفاءة فئول أداء العاملين. الفرض الفرعي الثالث: "توجد علاقة أثز ذات دلالة احصائية لبُعد الإجراءات الفعالة على

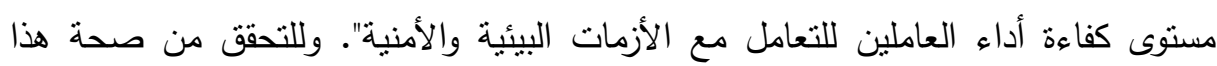
الفرض قام الباحث باستخدام الانحدار الخطي البسيط. 
جدول(1) 11 ): نتائج تحليل الانحدار الخطي البسيط لتأثثر بُعد الإجراءات الفعالة على مستوى

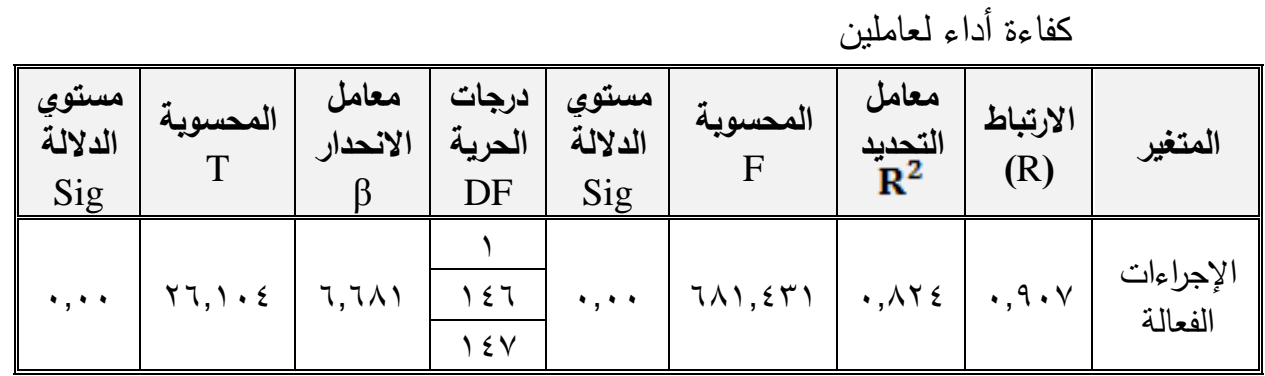

يوضح الجدول تأثير بُعد الإجراءات الفعالة على مستوى كفاءة أداء العاملين، إذ أظهرت

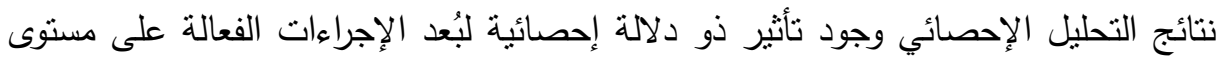

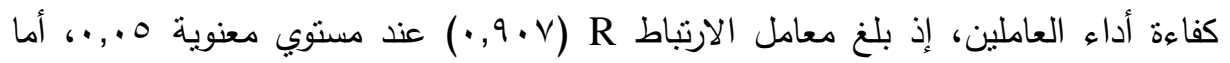

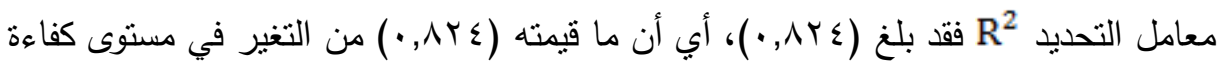

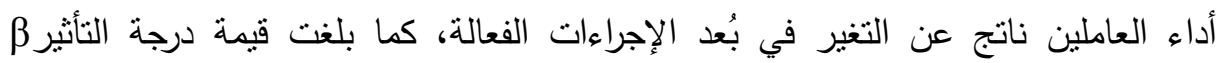

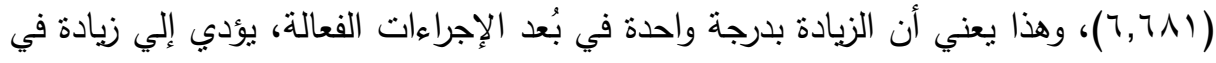

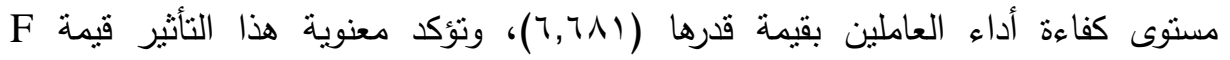

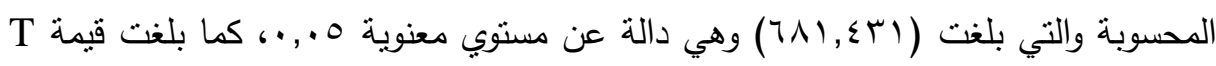

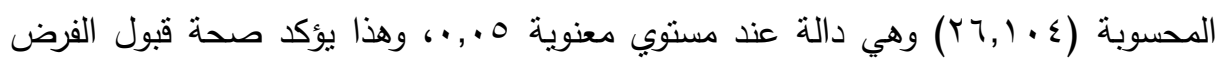

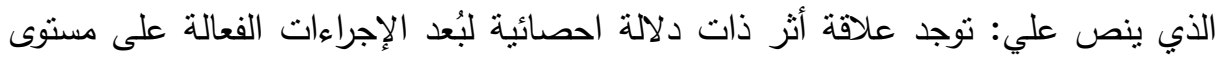
كفاءة أداء العاملين للتعامل مع الأزمات البيئية والأمنية . الفرض الفرعي الرابع: "توجد علاقة أثز ذات دلالة احصائية لبُعد الرقابة على مستوى كفاءة

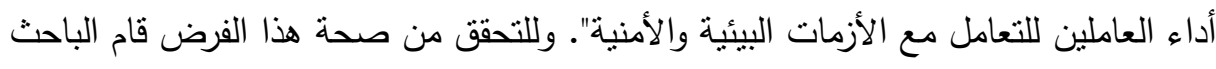
باستخدام الانحدار الخطي البسيط. 
جدول(Y I): نتائج تحليل الانحدار الخطي البسيط لتأثير بُعد الرقابة على مستوى كفاءة أداء

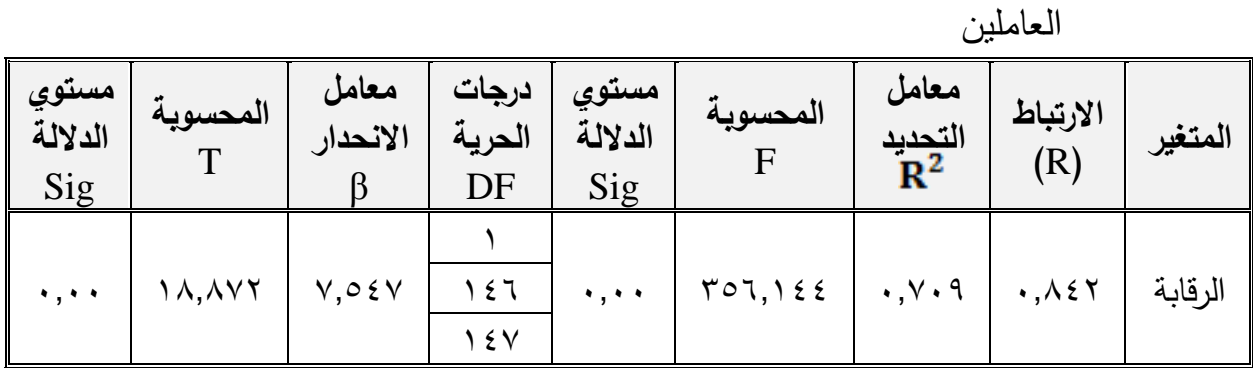

يوضح الجدول تأثير بُعد الرقابة على مستوى كفاءة أداء العاملين، إذ أظهرت نتائج التحليل الإحصائي وجود تأثثر ذو دلالة إحصائية لبُعد الرقابة على مستوى كفاءة أداء أداء

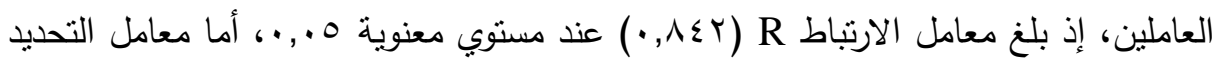

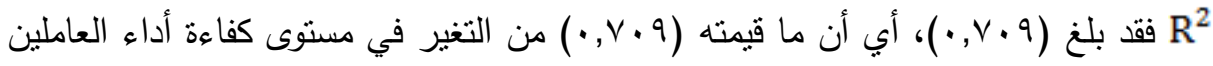

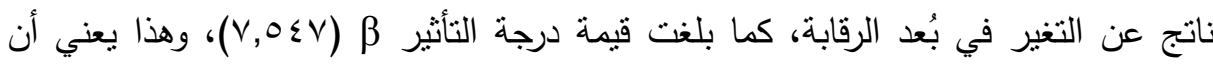

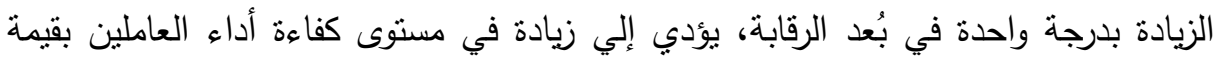

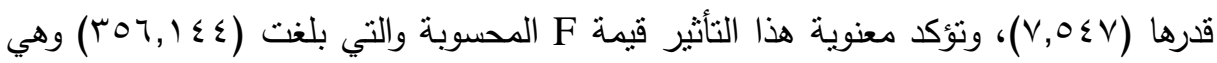

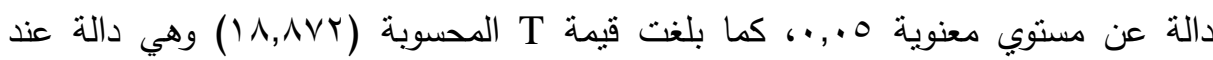
مستوي معنوية ه., •. ، وهذا يؤكد صحة قبول الفرض الذي ينص علي: توجد علاقة أثر ذات دلالة احصائية لبُعد الرقابة على مستوى كفاءة أداء العاملين للتعامل مع الأزمات البيئية والأمنية. الفرض الفرعي الخامس: "توجد علاقة أثر ذات دلالة احصائية لبُعد العرض والمراجعة على

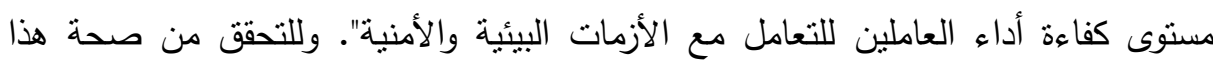
الفرض قام الباحث باستخدام الانحدار الخطي البسيط. 
جلول(r ا I): نتائج تحليل الانحدار الخطي البسيط لتأثثر بُعد العرض والمراجعة على مستوى

\begin{tabular}{|c|c|c|c|c|c|c|c|c|}
\hline مستوي & المحسوية & الانحدار & الحرية & الدلالة & المحسوية & $\begin{array}{l}\text { التصديد } \\
\mathbf{R}^{2}\end{array}$ & $\begin{array}{c}\text { الارتباط } \\
\text { (R) }\end{array}$ & المتثير \\
\hline \multirow[b]{2}{*}{$\cdot, \cdot \cdot$} & \multirow[b]{2}{*}{$17, \Gamma \leq \varepsilon$} & \multirow[b]{2}{*}{$0,1 \leqslant 7$} & $\frac{1}{1}$ & \multirow[b]{2}{*}{$\cdot, \cdot \cdot$} & \multirow[b]{2}{*}{$r \neg V, I r \varepsilon$} & \multirow[b]{2}{*}{$\cdot, T \leqslant V$} & \multirow[b]{2}{*}{$\cdot, \wedge \cdot \varepsilon$} & \multirow{2}{*}{ العراجعة } \\
\hline & & & $\frac{1 \leqslant 7}{1 \leqslant V}$ & & & & & \\
\hline
\end{tabular}

يوضح الجدول تأثثر بُعد العرض والمراجعة على مستوى كفاءة أداء العاملين، إذ أظهرت

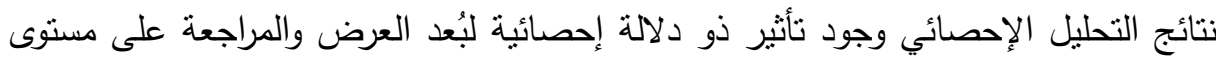

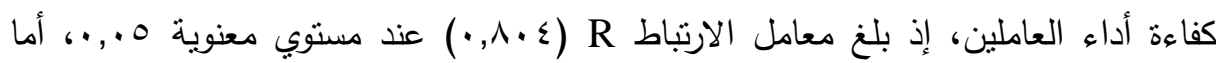

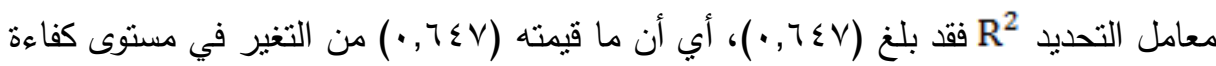

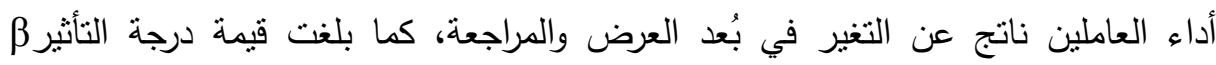

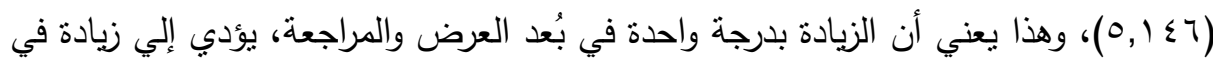

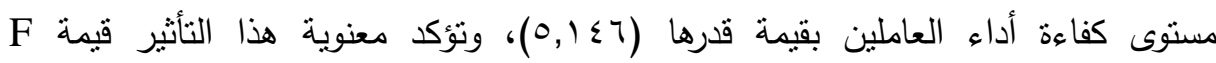

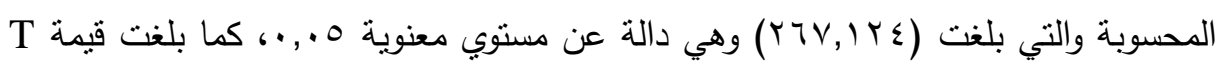

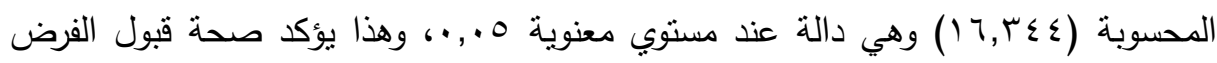

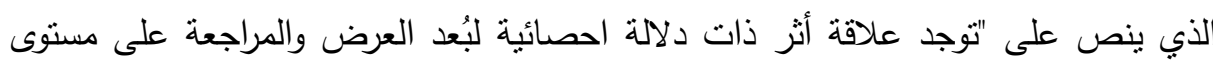
كفاءة أداء العاملين للتعامل مع الأزمات البيئية والأمنية". الفرض الفرعي السادس: "يوجد علاقة أثر ذات دلالة احصائية لبُعد الرصد والتطبيق على الثى

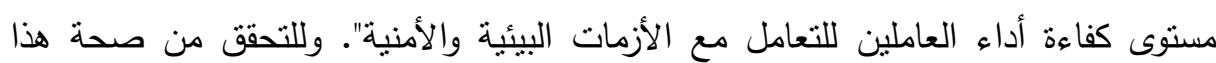
الفرض قام الباحث باستخدام الانحدار الخطي البسيط.

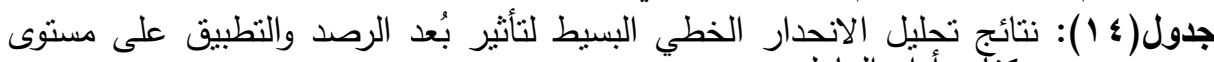

\begin{tabular}{|c|c|c|c|c|c|c|c|c|}
\hline مستوي & المحسوية & $\begin{array}{c}\text { الانحدار } \\
\beta \\
\end{array}$ & 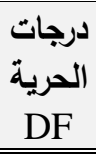 & مستوي & المحسوية F & التحديد & $\begin{array}{c}\text { الارتباط } \\
\text { (R) }\end{array}$ & المتغير \\
\hline \multirow[b]{2}{*}{$\cdot, \cdot$} & \multirow[b]{2}{*}{$r r, I r r$} & \multirow[b]{2}{*}{$7, \cdot V 7$} & 1 & \multirow[b]{2}{*}{$\cdot, \cdots$} & \multirow[b]{2}{*}{ Or $\varepsilon, T A Y$} & \multirow[b]{2}{*}{$\cdot, \vee \vee \wedge 4$} & \multirow[b]{2}{*}{ •, Аᄉ } & \multirow{2}{*}{ التطبيق } \\
\hline & & & $\frac{1 \leq 7}{1 \leqslant V}$ & & & & & \\
\hline
\end{tabular}


يوضح الجدول ثأثير بُعد الرصد والتطبيق على مستوى كفاءة أداء العاملين، إذ أظهرت

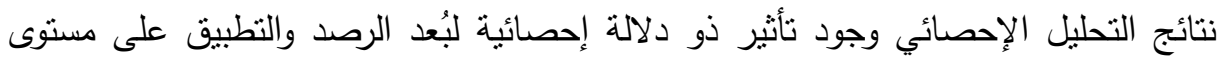

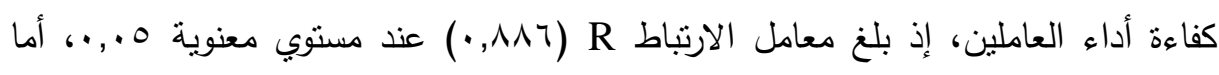

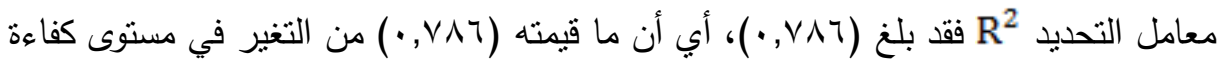

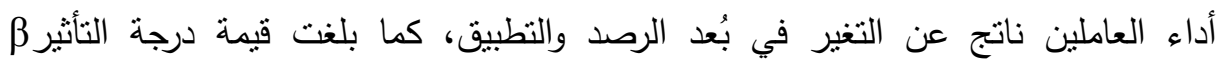

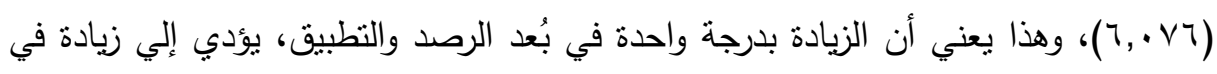

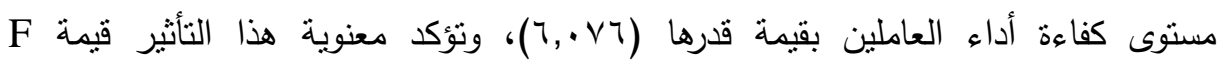

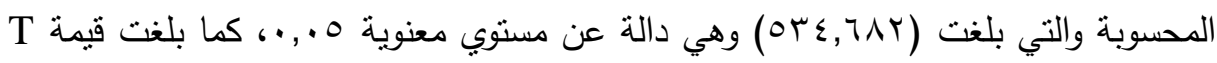

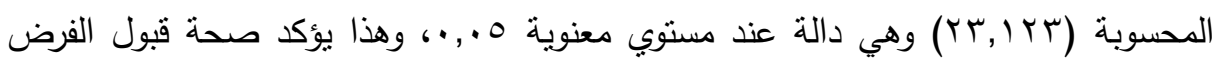

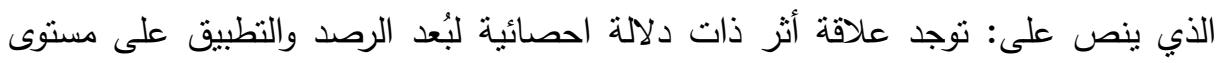
كفاءة أداء العاملين للتعامل مع الأزمات البيئية والأمنية. الفرضية الرئيسية الثالثة: "يوجد فروف ذات دلالة إحصائية في استجابات المستقصي

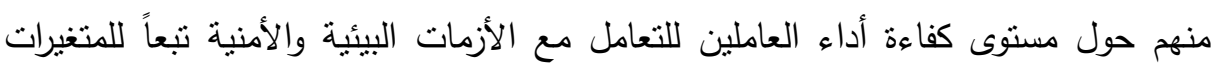
التالية (النوع، العمر ، المؤهل العلمي)". ولاختبار صحة هذه الفرضية نم استخدام اختبار (T) في حالات العينتين المستقلتين لاختبار الفروق التي تعزى لكتغير النوع، بينما تم استخدام اختبار تحليل التباين الأحادي (One way ANOVA) لاختبار الفروق التي تعزى للمتغيرات

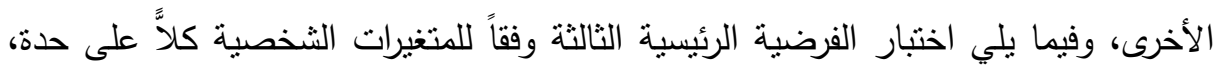

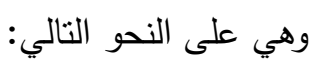

بالنسبة لمتغير النوع: المئ Independent Samples T-test قام الباحث باستخدام T-Test

\begin{tabular}{|c|c|c|c|c|c|c|c|}
\hline \multirow{2}{*}{ مستوي } & \multirow{2}{*}{ قالدلالة } & \multirow{2}{*}{ "تيمة } & \multicolumn{2}{|c|}{ إناث (ن = ه (0) } & \multicolumn{2}{|c|}{ ذكور (ن = } & \multirow{2}{*}{ المتغيرات } \\
\hline & & & الانحراف & المتوسط & الانحراف & المتوسط & \\
\hline غير & $\cdot, 1 \times 4$ & 1, & $0,9 \leqslant$. & 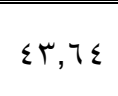 & (T, & $\varepsilon r, Y r$ & مستوى كفاءة أداء \\
\hline
\end{tabular}


أظهرت نتائج الجدول السابق عدم وجود فروق بين الذكور والإناث في مستوى كفاءة

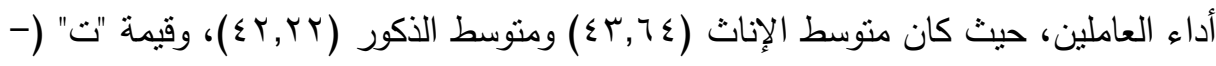

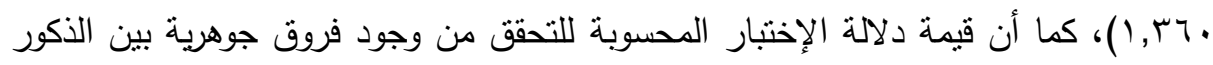

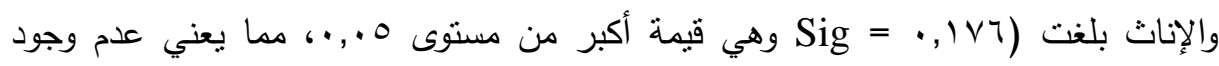
فروق جوهرية ذات دلالة إحصائية بين الذكور والإناث في بُعد مستوى كفاءة أداء العاملين. بالنسبة لمتغير العمر: One way ANOVA قام الباحث باستخدام ANOVA جدول(7 (1): نتائج اختبار الفروق في استجابات عينة الدراسة حسب متغير العمر

\begin{tabular}{|c|c|c|c|c|c|c|}
\hline قالدلة & قيمة & الانحراف & المتوسط & ن العدد 1 ا & العمر - ال & المتغيرات \\
\hline \multirow{4}{*}{$\cdot, r \leqslant V$} & \multirow{4}{*}{1,111} & 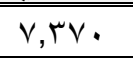 & $\varepsilon r, 10$ & Tr & أقل من ·r سنة & \multirow{4}{*}{ أداء العاملين كفاءة } \\
\hline & & $0, r V V$ & $\varepsilon r, \uparrow$. & 01 & • r الى •؛ سنة & \\
\hline & & 7,109 & $\leqslant 1,94$ & $\varepsilon \varepsilon$ & •ـ الى .0 سنة & \\
\hline & & $0,1 \cdot 0$ & $\varepsilon \cdot, V V$ & 11 & أكثز من ·0 سنة & \\
\hline
\end{tabular}

أظهرت نتائج الجدول السابق رقم عدم وجود فروق في مستوى كفاءة أداء العاملين تبعاً لمتغير العمر، حيث بلغت قيمة دلالة الإختبار المحسوبة للتحقق من وجود فروق جوهرية تبعاً

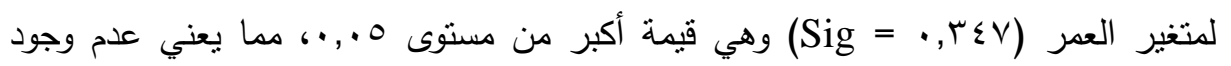
فروق جوهرية ذات دلالة إحصائية في مستوى كفاءة أداء العاملين للتعامل مع الأزمات البئية البيأية

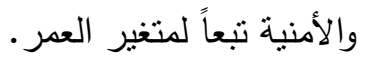

بالنسبة لمتغير المؤهل العلمي: One way ANOVA قام الباحث باستخدام ANOVA جدول(IV) بنائج اختبار الفروق في استجابات عينة الدراسة حسب متغير المؤهل العلمي

\begin{tabular}{|c|c|c|c|c|c|c|}
\hline قالدلاة & قيمة & الانعياري & المتوسط & ن العداد 1 ن 1 & المؤهل العلمي & المتغيرات \\
\hline \multirow{4}{*}{$\cdot, \varepsilon) \leqslant$} & \multirow{4}{*}{$\cdot, 97}$. & $\varepsilon, 9 \varepsilon$. & $\sum 1,0 \mathrm{~V}$ & $r \wedge$ & دبلوم & \multirow{4}{*}{ بيئة العمل أبعاد } \\
\hline & & $0, Y \leq 4$ & $\varepsilon \varepsilon, r$. & TV & ليسانس & \\
\hline & & $v, 197$ & $\{r, 01$ & 79 & بكالوريوس & \\
\hline & & $0, \pi 19$ & $\varepsilon r, 1 T$ & $r \varepsilon$ & دراسات عليا & \\
\hline
\end{tabular}


أظهرت نتائج الجدول السابق عدم وجود فروق في مستوى كفاءة أداء العاملين نبعاً

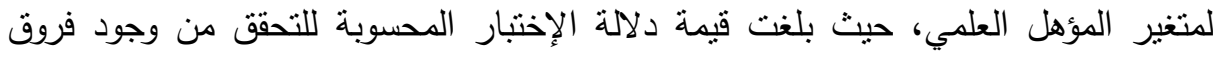

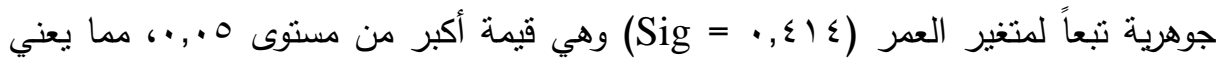

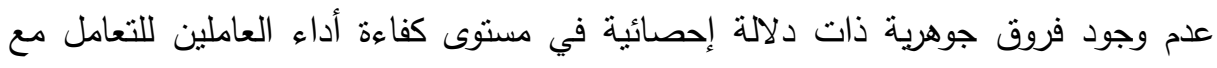

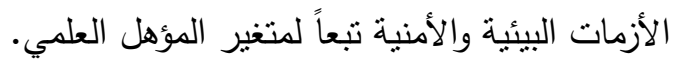

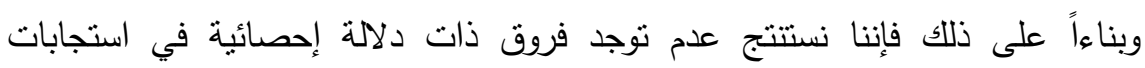
المسنقصي منهم حول مستوى كفاءة أداء العاملين للتعامل مع الأزمات البيئية والأمنية تبعاً

$$
\text { لمن النتائج التى توصل (النوع، العمر ، المؤهل العلمي). }
$$

ا. الإهتمام بالتدريب التنظيمى يؤدى لرفع كفاءة العاملين فى مواجهة الأزمات البيئية والأمنية

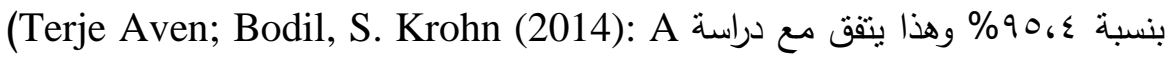
new perpective on how to understand assess and manage risk and the ضرورة التحسين المستمر فى الأداء والتدريبات على الأحداث غير unforeseen)

r. إهتمام شركة المصرية للإتصالات بأبعاد بيئة العمل التى تم التتويه بها (الرصد والتطبيق،

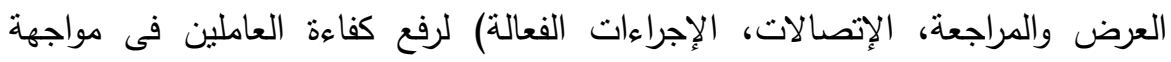

$$
\text { الأزمات البيئية والأمنية. }
$$

\section{اللموكيان}

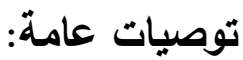

• • تعميم فكرة ادارة الأزمات البيئية والأمنية فى جميع الجهات الحكومية والخاصة. • عقد برامج تدريبية فى شركات الإتصالات والمجالات الأخرى للطلاب والطالبات بالجامعات قبل الإنتهاء من المرحلة الدراسية بالحياة العملية على كيفية مواجهة الأزمات البيئية والأمنية. 


\section{توصيات لثركات الإتصالات:}

• تفعيل بيئة عمل متكاملة من اتصالات وتدريب تتظيمى للعاملين: - من حيث الإتصالات: عمل روية مشتركة بين شركات الاتصالات وبعضها بوسائل اتصالات حديثة منل فيديو كونفرنس.

- من حيث التدريب التتظيمى: تحديد ميزانية مالية لعمل بيئة محاكاة للندريب الواقعى فئرئ للعاملين. توصيات للعاملين بشركات الإتصالات:

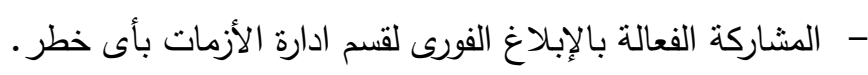
- التواصل المستمر داخليا بين العاملين. - الإهتمام بالتدريب المستمر والتطوير وقراءة النشرات وحضور الندوات الخاصة بطرق مواجهة الأزمات.

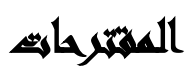

ينم تكوين فرق عمل إدارة الأزمات من المختصين وبعض العاملين الذين نم إختيارهم

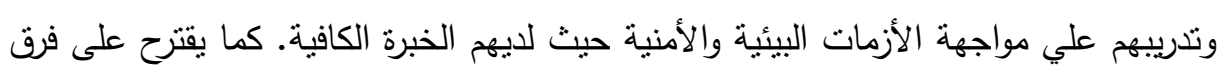

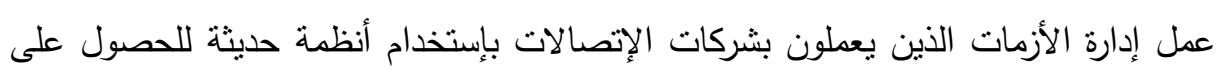
بيانات وتحويلها لـعلومات لإدارة الأزمات.

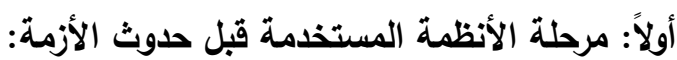

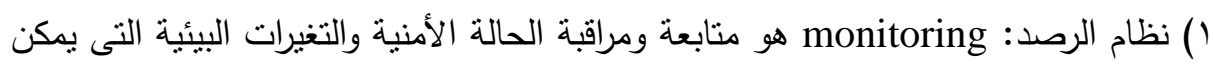
أن تحدث بالثركة عن طريق تركيب كاميرات مراقبة في الأماكن الضرورية خارج وداخل الثركة حتي تتمكن فرق عمل إدارة الأزمات متابعة الحالة بالثركة.

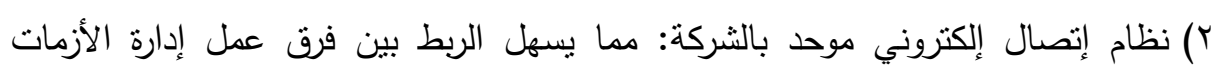

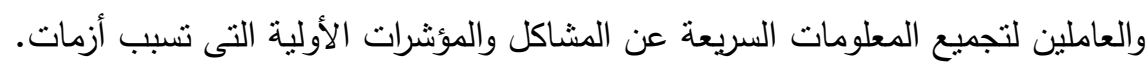

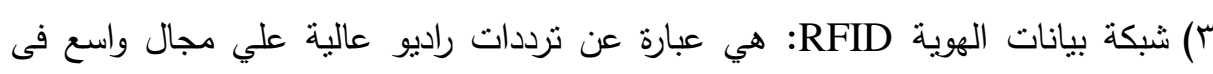

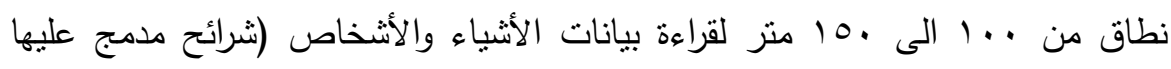


بيانات ومعلومات يتم قرائتها عن طريق الترددات لإستقبالها على جهاز، لتجميع بيانات عن العاملين وعددهم يتم ربطه بشبكة واي فاي او بيانات انترنت، مثال: هذا النظام بسهل معرفة عدد وبيانات العاملين في مكان الأزمة لتقدير الموقف.

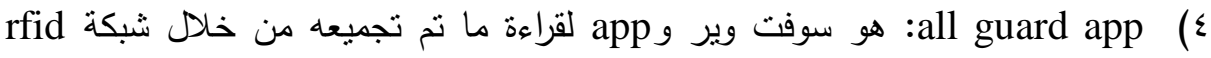
وتتبع جميع العاملين وحصر عدد العاملين أثناء عملية الإخلاء على شاشة الجهاز الحاسب كخريطة للمكان.

0) نظام المعلومات الجغرافي للمكان: هو نظام ينم إستخدام شبكة الإنترنت بأماكن محددة في الثركة لإرسال إثنارات ومعلومات كافية لفرق عمل إدارة الأزمات حتي تتمكن من متابعة

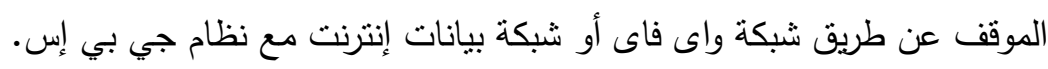

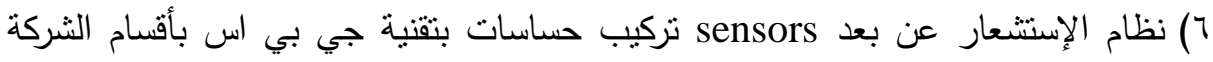

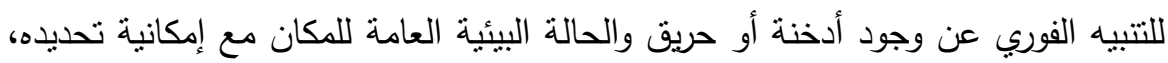
هذا النظام يستخدم فى نظام المعلومات الجغرافي. V نظام إتصال خارجي مرئي:Video conference هو نظام يسهل الإجنماع مع شركات الإتصالات المماثلة لتبادل الخبرات وعرض مقنرحات علي كيفية إدارة الأزمات البيئية

(^) هى شبكة تم إطلاقها فى كندا، تشغيلها

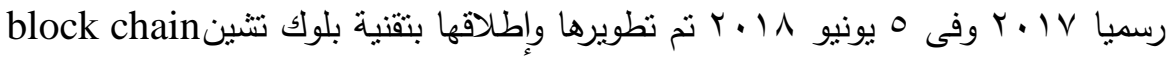

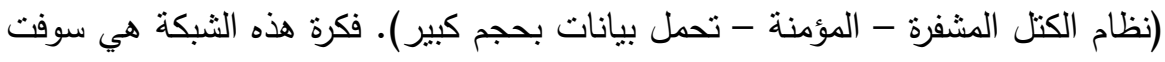
وير أو .app يسهل لفريق إدارة الأزمات مهامه بسرعة ومهارة من إجراء (مكالمات فيديو

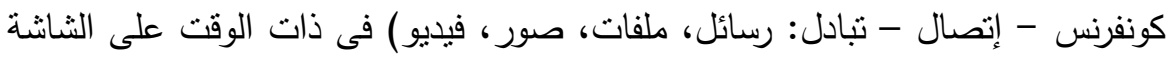
مع عدد من الفريق، ويمكن أيضا ربط العاملين بتلك الثبكة للإستغاثة وتبادل المقترحات. 
ثانياً: مرحلة التدريب الواقعي قبل حدوث الأزمة:

Simulation (

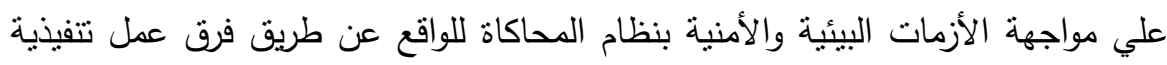

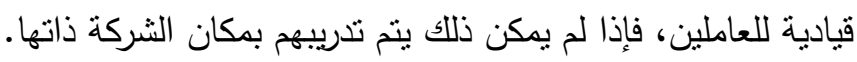
r) يتم عمل رسومات بتقنية الم Dr بنظام computer aid design خريطة لموقع التدريب وتجميعها إلكترونيا للوصول إليها مرة أخري لعمل مراجعة وتطوير من الأداء.

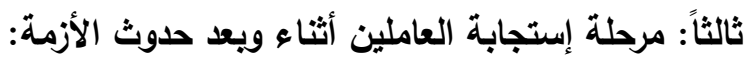
() استخدام برنامج Tango: هو تطبيق على الهاتف المحمول حيث أن فكرة هذا البرنامج

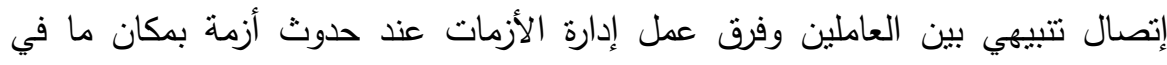
الثركة نظرا لإتساع المبني، سيتم إرسال live video call من العاملين المستغيثين لفرق

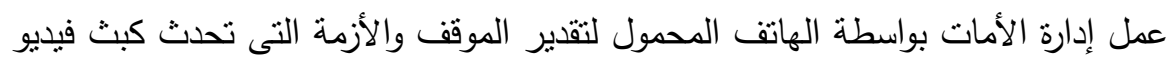
مباشر من مكان الأزمة حين وقوعها حتى يتمكن الفرق من توجيه الأعداد والمعدات المناسبة للواقعة.

r) استخدام برنامج SOS هو تطبيق على الهاتف المحمول حيث أن فكرة هذا البرنامج

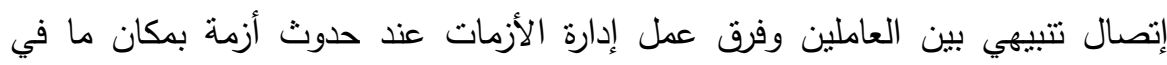

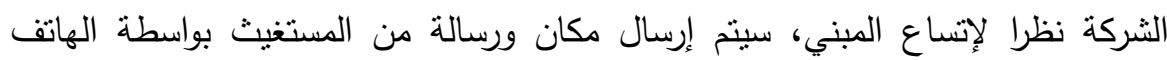

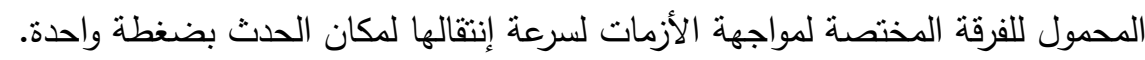

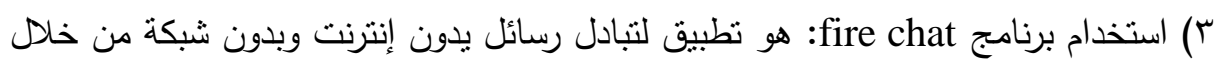
تتغيل الواى فاى من الهاتف المحمول وإرسال استغاثة، من مميزاته إرسال العاملين لبعضهم وأقرب مكتب بالثركة يرسل لفرق عمل إدارة الأزمات عند إنقطاع الثبكة أثناء

$$
\text { حدوث الأزمة. }
$$

رابعاً: مرحلة إستجابة العاملين بعد حدوث الأزمة: نواصل العاملين: بعد الإنتهاء من عملية

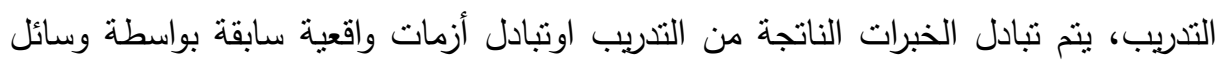

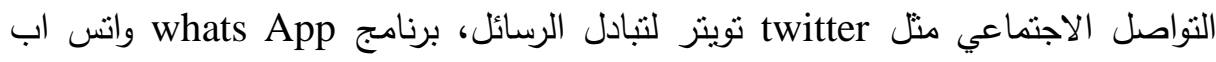

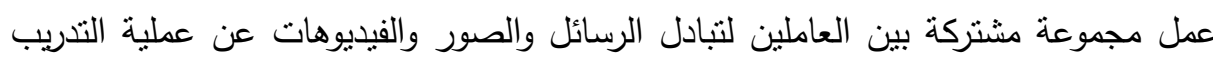

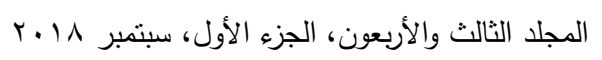


والأراء المختلفة لديهم، برنامج flicker فليكر تبادل فيديوهات المحاكاة لعملية التدريب وهكذا. وأخيراً ربط نلك الأشياء من وسائل وأنظمة مستخدمة بشبكة أنترنت موحدة لسهولة التحكم

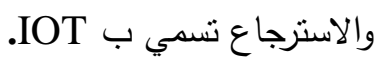

\section{zall}

إجلال عبد المنعم حافظ، عبد المنعم محمد السعيد؛ مصطفى كمال وهبة (r إ. r): أصول ومبادىء الإدارة، ماس للطباعة المعن

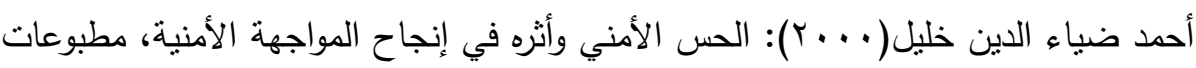
كلية الثرطة، القاهرة

أحمد عزمي زكى(0 . . ץ): دور النقابات فى تحسين جودة الحياة الوظيفية للعاملين، رسالة ماجستير غير منشورة، كلية التجارة، جامعة قناة السويس.

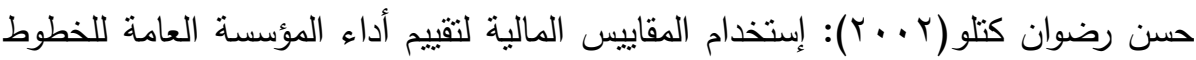
الحديدية السورية، رسالة ماجستير غير منشورة، جامعة عين شمس.

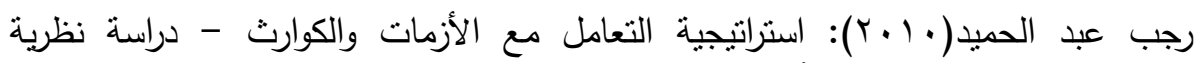
وتطبيقية، دار أبو المجد للطباعة بالهرم

صلاح محمود الحجار : نظام الإدارة البيئية والتكنولوجية، دار الفكر العربي.

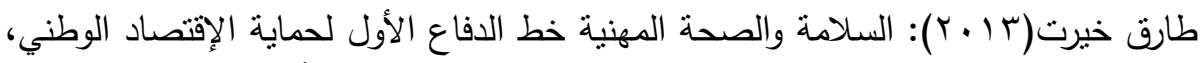

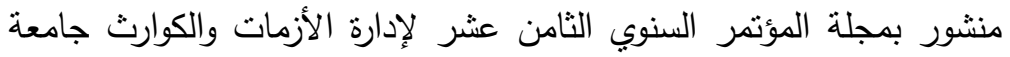
عين شمس، القاهرة.

عايدة سيد خطاب: الإدارة الإستراتيجية المنقدمة، كلية التجارة، جامعة عين شمس، مكتبة

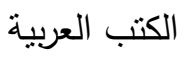

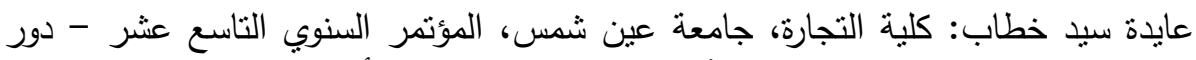

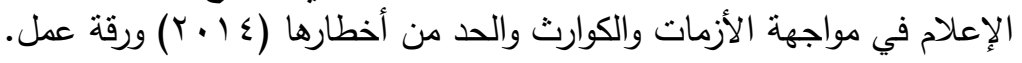

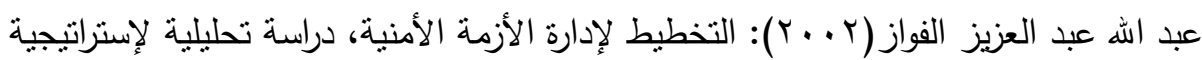

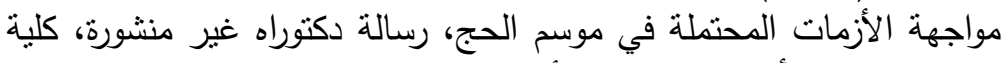
الدراسات العليا، أكاديمية مبارك للأهن.

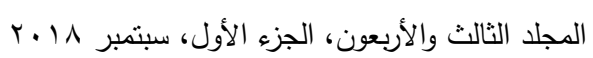


عجب فهيد سعيد الهاجري(9 . . ץ): نموذج مقترح لتقييم الأداء لصناعة السياحة فى دولة

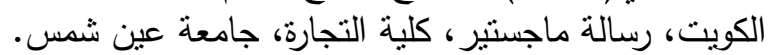

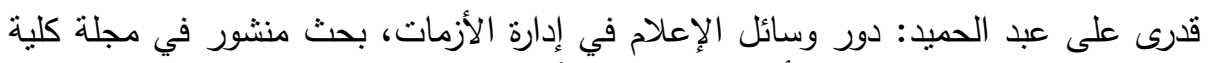

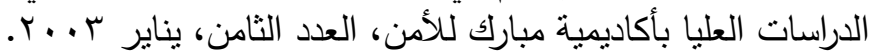

محمد حافظ الرهوان: التخطيط لمواجهة الأزمات والكوارث ومكافحة الإرهاب - دراسة تطبيقية، القاهرة

محمد رشاد الحملاوي وسماحة السيد محمود: إدارة الأزمات، مراجعة إجلال عبد المنعم حافظ،

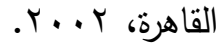

محمد سالم( ץ): الإدارة المعاصرة، كلية التجارة، جامعة عين شمس، دار شركة الحريري للطباعة

محمد عبد التواب شاهين( . . ب): الآثار السيكولوجية الناتجة عن إدارة الأزمات والكوارث

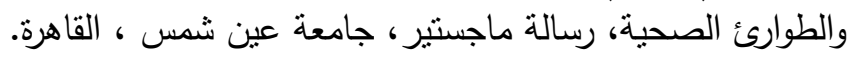

محمد ندا: الوقاية من الأزمات والكوارث - بدون سنة نشر - النانر : شركة القصر للطباعة

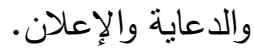

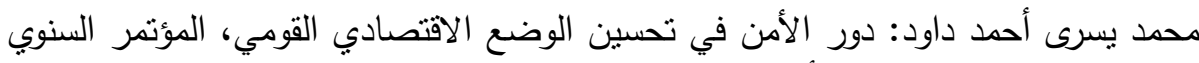

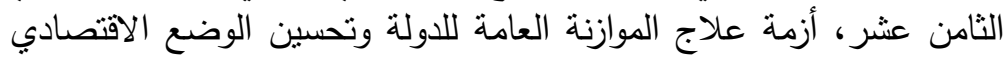
بجامعة عين شمس.

محمود جاد الله: إدارة الأزمات، دار أسامة للنشر والتوزيع، عمان، الأردن، بدون سنة نشر مكتبة جامعة عين شمس، كلية التجارة.

مني صلاح الدين شريف(991 ()): إدارة الأزمات الوسيلة للبقاء، البيان للطباعة والنشر ، القاهرة

نورا مصطفى عبد السلام أبو العلا(T 1 ـ ب): أثز فعالية إدارة المخاطر على ربح السهم لتنشيط

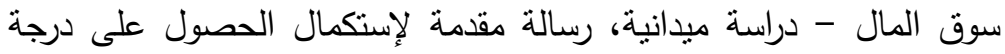
الماجستير في المحاسبة.

هبه مصطفي كمال(r ( • ب): مبادئ التظظيم والإدارة، كلية التجارة جامعة عين شمس، الطبعة

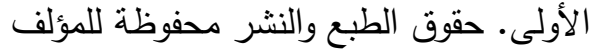

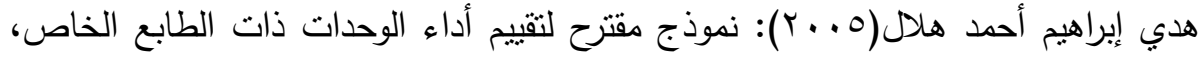

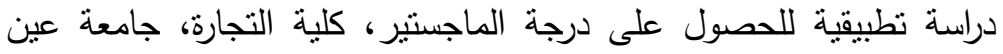


Adham Hany Abulnour (Aug. 2014): Towards efficient disaster management in Egypt, HBRC journal, Vol. 10, Issue 2.

Jing Xin and Chongfu Huang (Nov. 2013): Fire risk analysis of residential buildings based on scenario clusters and its application in fire risk management, Fire Safety Journal, Vol. 62, part A.

Katerina Vichova; Martin Hromada and David Rehak (2017): The Use of Crisis Management Information Systems In Rescue Operations of Fire Rescue Services of the Czech Republic, Original Research Article Procedia Engineering. Vol. 192.

Olufunsho Awodele; Temidayo, D. Popoola; Akin Akinyede; Bawo, S. Ogbudu; Akin Akinyede; Herbert, A. B. Coker and Alade Akintonwa (June 2014); Occupational Hazards and safety measures Amongst the paint Factory Workers in Lagos, Nigeria. safety and health at work open access, Vol. 5, Iss. 2

Runjiao Liu; Difei Jiang and Lei Shi (March 2016): Agent-based simulation of alternative classroom evacuation scenarios. Vol. 5, issue 1.

Shaharam Mahoudi; Fakhradin Ghasemi; Iraj Mohammadfam and Esamaeil Soleimani (Sept. 2014): Framework for continuous assessment and improvement of occupational health and safety issues in construction companies, original research Article safety and health at work. Vol. 5, iss. 3.

Terje Aven and Bodil, S. Krohn (Jan. 2014): A new perspective on how to understand assess and manage risk and the unforeseen, original research Article reliability Engineering \& system safety. Vol. 121.

crisisthinking.co.uk.

WWW.gdocd.gov.ae.

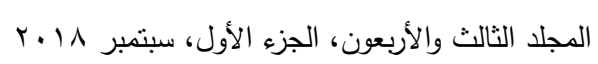


أحمد محمد محمد البهنساوي وآخرون

\title{
PROPOSED STRATEGY TO RAISE EFFICIENCY OF EMPLOYEES IN TELECOM COMPANIES TO DEAL WITH ENVIRONMENTAL AND SECURITY CRISIS PRACTICAL STUDY IN EGYPT TELECOM INSTITUTION
}

El Bahnasawy, A. M. ${ }^{(1)}$; Khatab, G. ${ }^{(2)}$ and El Berry, Amany ${ }^{(2)}$ 1) Institute of Environmental Studies and Research, Ain Shams University 2) Faculty of Commerce, Ain Shams University

\begin{abstract}
The role of telecom companies of important roles in the daily life of wich should be given to the business continuity in telecom companies. Most of telecom companies didn't care about training employees to deal with environmental and security crisis which can be exposed to it, which threatens its survival, continuity and impacts reputation. This research targets to achieve high efficiency for employees to deal with environmental and security crisis and review proposal for telecom compnies.

This study takes the descriptive, analytical approach, deductive, interviews and the accurate scientific noticing for reaching right results from the actual sample of (148) employers, distributed survey and tested advavced in telecom Egypt company (smart village) for reaching and inform the level of employers training and their efficiencies to handle crisis.

General recommendations: all governmental agencigees and private agencies must mainstream (management of environmental and security crisis). University students must attend training programs in telecom companies and other work fields before the end of their study phase about confronting environmental and security crisis. As recommendations for telecom companies: it must be activate an

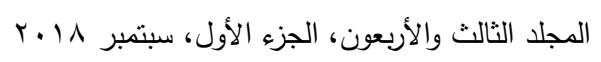




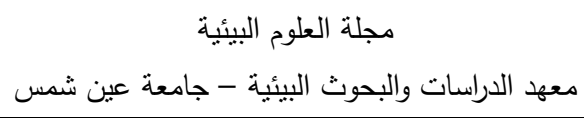

integrated business environment of communications and organizational training for employers. Communications: telecom companies must take common vision with modern telecom tools as video conference. Organizational training: identify financial budget to elaborate real training environmental simulationfor employers. Recommendations for employers in telecom companies: it must be found effective engagement and instant notification in risk state to crisis management section. It is a must for employers to communicate continually in organization. It must concerned by continually training, development and attending seminars about confronting crisis methods.

Conclusion: organizational training lead to raise the efficiency of employers in confronting of rnvironmental and security crisis with ratio 95\% 2- telecom Egypt company is concerning by dimensions of work environment (monitoring and implementation - auditing and reviewing - telecommunications - effective procedures) to raise the efficiency of employers in confronting of rnvironmental and security crisis. Environment work lead to improvement of performance of employers and according the study field, the total influencing of environmental work on the employers efficiency is $98 \%$. 